\title{
The EarthCARE satellite: the next step forward in global measurements of clouds, aerosols, precipitation, and radiation
}

Article

Published Version

Illingworth, A. J., Barker, H. W., Beljaars, A., Ceccaldi, M., Chepfer, H., Clerbaux, N., Cole, J., Delanoë, J., Domenech, C., Donovan, D. P., Fukuda, S., Hirakata, M., Hogan, R. J., Huenerbein, A., Kollias, P., Kubota, T., Nakajima, T., Nakajima, T. Y., Nishizawa, T., Ohno, Y., Okamoto, H., Oki, R., Sato, K., Satoh, M., Shephard, M. W., Velázquez-Blázquez, A., Wandinger, U., Wehr, T. and van Zadelhoff, G.-J. (2015) The EarthCARE satellite: the next step forward in global measurements of clouds, aerosols, precipitation, and radiation. Bulletin of the American Meteorological Society, 96 (8). pp. 1311-1332. ISSN 1520-0477 doi: https://doi.org/10.1175/BAMS-D-12-00227.1 Available at https://centaur.reading.ac.uk/55938/

It is advisable to refer to the publisher's version if you intend to cite from the work. See Guidance on citing.

Published version at: http://dx.doi.org/10.1175/BAMS-D-12-00227.1

To link to this article DOI: http://dx.doi.org/10.1175/BAMS-D-12-00227.1

Publisher: American Meteorological Society 
All outputs in CentAUR are protected by Intellectual Property Rights law, including copyright law. Copyright and IPR is retained by the creators or other copyright holders. Terms and conditions for use of this material are defined in the End User Agreement.

\section{www.reading.ac.uk/centaur}

\section{CentAUR}

Central Archive at the University of Reading

Reading's research outputs online 


\title{
THE EARTHCARE SATELLITE The Next Step Forward in Global Measurements of Clouds, Aerosols, Precipitation, and Radiation
}

\author{
by A. J. Illingworth, H. W. Barker, A. Beljatrs, M. Cecccaldi, H. Chepfer, N. Clerbaux, J. Cole, \\ J. Delanoë, C. Domenech, D. P. Donovan, S. Fukuda, M. Hirakata, R. J. Hogan, A. Huenerbein, \\ P. Kollias, T. Kubota, T. Nakajima, T.Y. Nakajima, T. Nishizawa, Y. Ohno, H. OKamoto, R. Oki, K. Sato, \\ M. Satoh, M.W. Shephard, A. Velázquez-Blázquez, U. Wandinger, T. Wehr, and G.-J. van Zadelhoff
}

\author{
EarthCARE, a joint ESA-JAXA satellite to be launched in 2018, will provide \\ global profiles of clouds, aerosols, and precipitation properties together \\ with derived radiative fluxes and heating rates.
}

T he Earth Clouds, Aerosol and Radiation Explorer (EarthCARE) satellite is a joint mission by the European Space and Japanese Aerospace Exploration Agencies scheduled for launch in 2018. Data from its cloud profiling radar, with Doppler capability, high-spectral-resolution lidar, and multispectral imager will be used to retrieve global profiles of cloud, aerosol, and precipitation properties. Radiation fields predicted from these profiles will be compared with observations made by its broadband radiometer. These data will be used to evaluate the representation of clouds, aerosol, precipitation, and associated radiative fluxes within climate and weather forecasting models and to assess if different, more physically
AFFILIATIONS: ILLINGWORTH-Department of Meteorology, University of Reading, Reading, United Kingdom; BARKER, COLE, AND ShePHARD - Environment Canada, Toronto, Ontario, Canada; BeLJAARS-European Centre for Medium-Range Weather Forecasts, Reading, United Kingdom; CeCCALDI ANd DeLANOË-LATMOS/ UVSQ/ISPL/CNRS, Guyancourt, France; CHEPFER-Laboratoire de Meteorologie Dynamique, Paris, France; Clerbaux and VelÁzQuezBLÁZQUEZ-Royal Meteorological Institute of Belgium, Brussels, Belgium; DOMENECH—Institute for Space Sciences, Free University of Berlin, Berlin, Germany; Donovan AND VAN ZADELhoff-Royal Netherlands Meteorological Institute, De Bilt, Netherlands; FuKUDA, HiRAKata, Kubota, AND OKI-Earth Observation Research Center, Japan Aerospace Exploration Agency, Ibaraki, Japan; HogaN-Department of Meteorology, University of Reading, and European Centre for Medium-Range Weather Forecasts, Reading, United Kingdom; HUENERBEIN AND WANDINGER-Leibniz Institute for Tropospheric Research, Leipzig, Germany; KolliAs-Department of Atmospheric and Oceanic Sciences, McGill University, Montreal, Quebec, Canada; T. NAKAJIMA AND SATOH-Atmosphere and Ocean
Research Institute, University of Tokyo, Tokyo, Japan; T. Y. NAKAJIMAResearch and Information Center (TRIC), Tokai University, Tokyo, Japan; NisHiZAWA-Center for Environmental Measurement and Analysis, National Institute for Environmental Studies, Tsukuba, Japan; OHNO-Applied Electromagnetic Research Institute, National Institute of Information and Communications Technology, Tokyo, Japan; Окамото AND SATO-Research Institute for Applied Mechanics, Kyushu University, Fukuoka, Japan; WEHR-ESA, ESTEC, Noordwijk, Netherlands

CORRESPONDING AUTHOR: Anthony J. Illingworth, Department of Meteorology, University of Reading, Earley Gate, P.O. Box 243, Reading RG6 6BB, United Kingdom

E-mail: a.j.illingworth@reading.ac.uk

The abstract for this article can be found in this issue, following the table of contents.

DOI:I0.II75/BAMS-D-12-00227.I

In final form 31 October 2014

@2015 American Meteorological Society 
based, parameterization schemes within the models can improve these representations.

The Fifth Assessment Report (AR5) of the Intergovernmental Panel on Climate Change (IPCC) (IPCC 2013) states that "Climate models now include more cloud and aerosol processes, and their interactions, than at the time of AR4, but there remains low confidence in the representativity and quantification of these processes in models." Moreover, the largest single cause of uncertainty in anthropogenic radiative forcing is from the indirect effect of aerosols on clouds; estimates range between -1.33 and $-0.06 \mathrm{~W} \mathrm{~m}^{-2}$. Figure 1 shows the range of predicted changes of cloud radiative forcing $\left(2.5 \mathrm{~W} \mathrm{~m}^{-2}\right)$ between 2006 and 2100 for eight Coupled Model Intercomparison Project (CMIP5) models each forced with the same emissions and forecasting a $3.7 \pm 1 \mathrm{~K}$ temperature increase, whereas the direct radiative forcing from doubling $\mathrm{CO}_{2}$ is estimated at $3.7 \mathrm{~W} \mathrm{~m}^{-2}$. A recent white paper on "grand challenges" (Bony and Stevens 2012) emphasizes the importance of the interactions between clouds, greenhouses gases, and aerosols in a changing climate. Global numerical weather prediction models have made enormous strides over the past decade and most are expected to have a resolution of $8 \mathrm{~km}$, or better, when EarthCARE is launched. The remarkable ability of the $3.5-\mathrm{km}$-gridded Nonhydrostatic Icosehedral Atmospheric Model (NICAM), with forward simulations by the Joint Simulator, to represent the Tropical Cyclone Fengsheng is displayed in Fig. 2 (Hashino et al. 2013). The close similarity between the forward-modeled and observed radar and lidar profiles indicates their potential for use in data assimilation, as has indeed been demonstrated by Janisková et al. (2012).

EarthCARE can be considered an evolution of the very successful CloudSat (Stephens et al. 2008) and Cloud-Aerosol Lidar and Infrared Pathfinder Satellite Observations (CALIPSO; Winker et al. 2010), which were launched into the A-Train constellation in 2006 in a 705-km orbit. CloudSat's $94-\mathrm{GHz}$ cloud radar and Cloud-Aerosol Lidar with Orthogonal Polarization (CALIOP) measure global profiles of cloud and aerosol properties. When combined with other instruments in the A-Train such as the Moderate Resolution Imaging Spectroradiometer (MODIS) and top-of-atmosphere (TOA) fluxes inferred from Clouds and the Earth's Radiant Energy System (CERES), they give a detailed picture of the global distributions of clouds and aerosols and how they interact with radiation and the hydrological cycle.

These data have been used in many multimodel evaluations. For example, Koffi et al. (2012) analyzed the aerosol distribution in 20 global aerosol models and found they overestimated the extinction above 6-km height; Nam et al. (2012) compared eleven climate models and found that tropical boundary layer clouds were 'too few and too bright'; Li et al. (2013) reported that the mean annual ice water path in 19 climate models varied by factors of $2-10$, and Li et al. (2012) looked at 20 models and discovered regional radiation biases in annual mean fluxes of up to $\pm 30 \mathrm{~W} \mathrm{~m}^{-2}$. In terms of addressing model physics, the data have been used to show how replacing diagnostic ice with a prognostic scheme results in a better ice water distribution (Delanoë et al. 2011) and have identified that the "autoconversion" term in

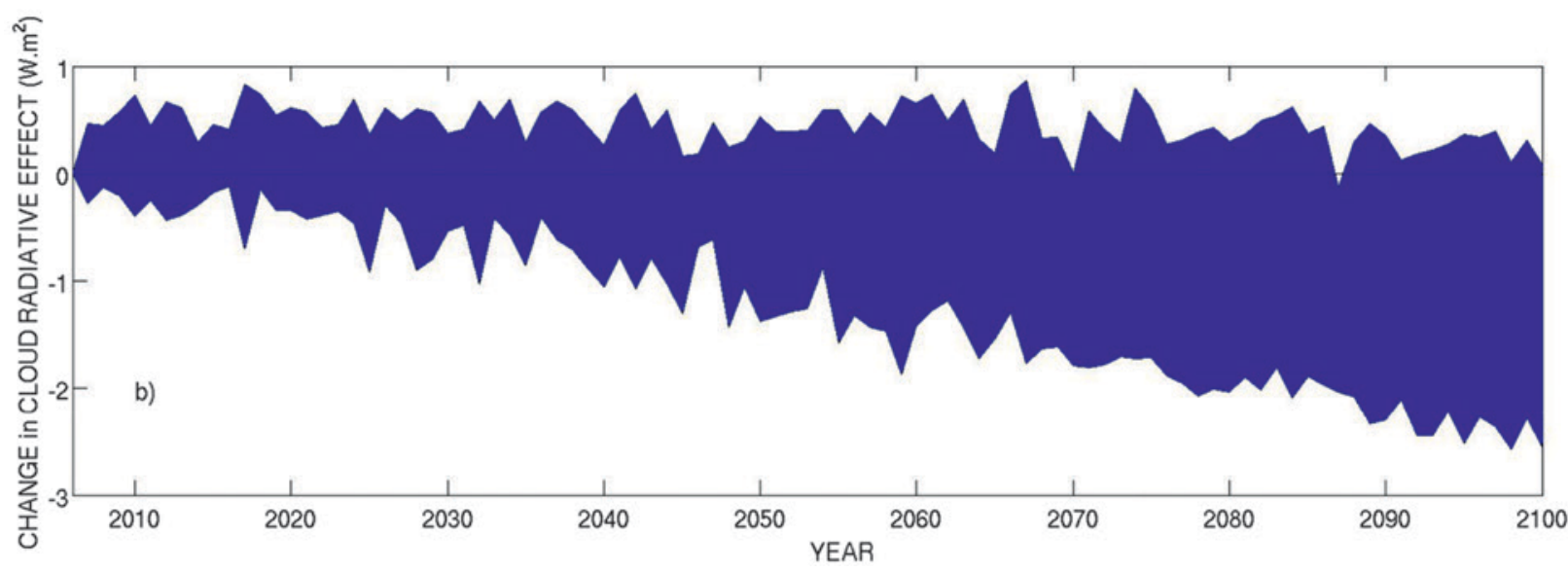

FIG. I. The range of the change in cloud radiative effects predicted from 2006 to 2100 from eight different models for the same $\mathrm{CO}_{2}$ increase and associated with global temperature rises of between 2.7 and $4.7 \mathrm{~K}$ depending on the model. The oscillations in the envelope show the large interannual variability. Several papers (e.g., Dufresne and Bony 2008) have shown that more than $70 \%$ of this intermodel spread on global mean temperature increase is due to uncertainty on cloud feedback. 
most models converts cloud liquid water to rain too rapidly (Suzuki et al. 2010). The data have further been used to provide the first global climatology of snowfall (Liu 2008) and light rainfall over the ocean (Berg et al. 2010) and have been used to quantify the radiative impact of subvisual cirrus (Sun et al. 2011). Zhang et al. (2010) report that over $30 \%$ of midlevel clouds have a thin layer of supercooled liquid at cloud top; these layers have a strong radiative effect but are absent in the climate models. In the next sections, we discuss how the observations from EarthCARE may help to resolve some of the model discrepancies.

\section{THE FOUR EARTHCARE INSTRUMENTS AND SINGLE-SENSOR ALGORITHMS.}

Overview. EarthCARE will carry four instruments on a single platform in a $393-\mathrm{km}$ orbit. Table 1 provides a brief summary of EarthCARE's instruments; Fig. 3 describes instrument sampling geometries and the orbit. The 355-nm high-spectral-resolution lidar(HSRL) will separate the backscatter return from

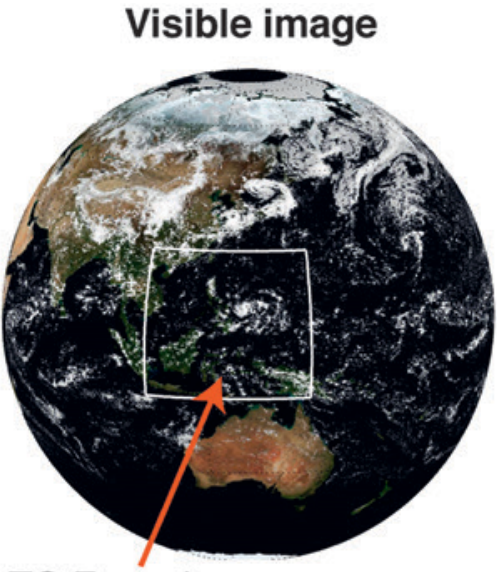

TC Fengsheng<smiles>C1C2CC12</smiles>

Brightness temp $10.8 \mu \mathrm{m}$
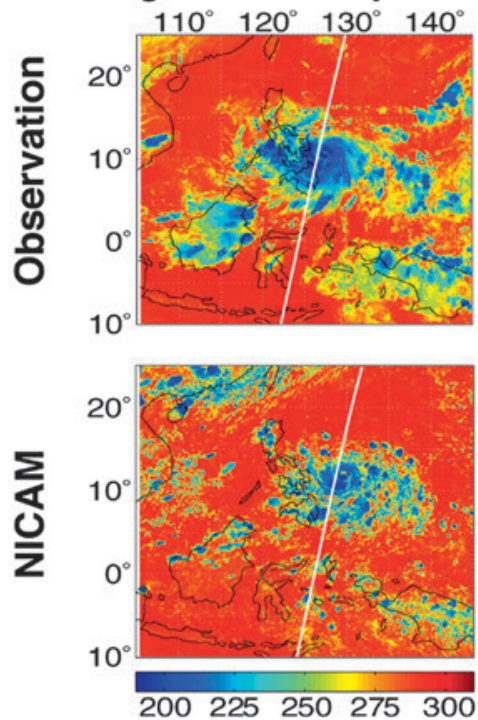

Longwave flux
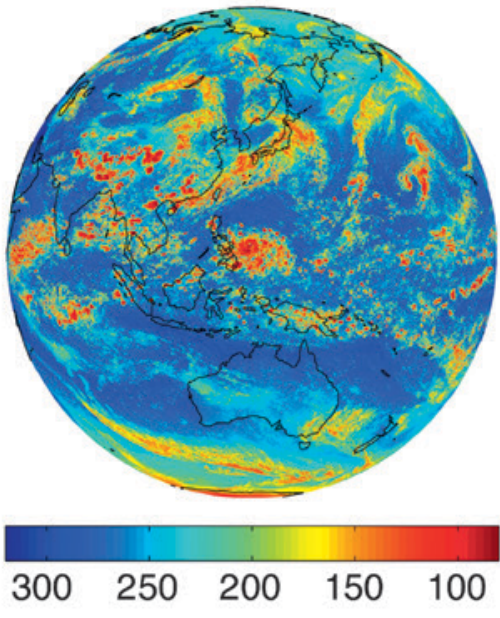

CloudSAT $94 \mathrm{GHz}$
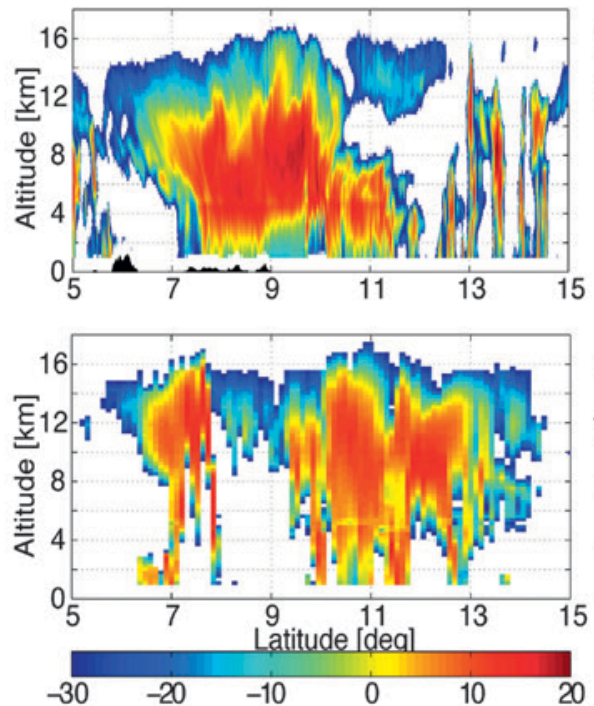

CloudSAT $94 \mathrm{GHz}$

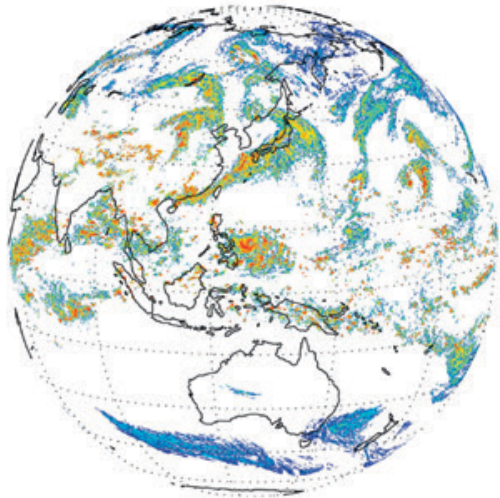

Fig. 2. Global simulation by the 3.5-km-gridded NICAM model: (top) simulated visible radiances, TOA upward longwave flux $\left(\mathrm{W} \mathrm{m}^{-2}\right)$, and $94-\mathrm{GHz}$ CPR signal (dBZ) on 18 Jun 2008. For the visible image, the cloudy-sky RGB was created with simulated MODIS I, 4, and 3 band radiances, and the clear-sky part was filled with Blue Marble: Next Generation (http://earthobservatory.nasa.gov/Features/BlueMarble/). (bottom) Regional segments of observed and simulated brightness temperature at $10.8 \mu \mathrm{m}(\mathrm{K})$ with a Tropical Cyclone Fengsheng and height-distant cross sections for CPR (dBZ) and lidar $\left(\log 10\right.$ of $\left.\mathrm{I} \mathrm{m}^{-1} \mathrm{sr}^{-1}\right)$ signals along the CloudSat orbit (white line) on 18 Jun 2008. The observed brightness temperature was taken from Himawari. 
TABLE I. The specifications of the four EarthCARE instruments and examples of the products.

\begin{tabular}{|c|c|c|}
\hline Instrument & Characteristics & Example products and synergy \\
\hline $\begin{array}{l}\text { Atmospheric lidar } \\
\text { (ATLID) } 355 \mathrm{~nm}\end{array}$ & $\begin{array}{l}\text { Transmits } 38 \mathrm{~mJ} \text { pulses at } 5 \mathrm{I} \mathrm{Hz} \text {. High-spectral-resolution } \\
\text { receiver with Rayleigh and Mie copolar and total cross- } \\
\text { polar channels. Telescope diameter } 0.62 \mathrm{~m} \text {. Beam divergence } \\
45 \mu \mathrm{rad} \text {, ground footprint about } 30 \mathrm{~m} \text {. Receiver field of view } \\
65 \mu \mathrm{rad} \text {. Pointing } 3^{\circ} \text { off-nadir along track to avoid specular } \\
\text { reflection from ice crystals. Vertical-resolution } 103 \mathrm{~m} \text { from -I } \\
\text { to } 20 \mathrm{~km} \text { in height and } 500 \mathrm{~m} \text { from } 20 \text { to } 40 \mathrm{~km} \text {. Horizontal } \\
\text { resolution } 285 \mathrm{~m} \text { (two shots). }\end{array}$ & $\begin{array}{l}\text { Aerosol products: profiles of extinction, } \\
\text { backscatter, depolarization ratio, lidar } \\
\text { ratio (all with uncertainties), and } \\
\text { aerosol type. Cloud products: IWC, } \\
\text { effective radius, cloud-top height, cloud } \\
\text { and aerosol synergy products with } \\
\text { CPR and MSI. }\end{array}$ \\
\hline $\begin{array}{l}\text { Cloud profiling } \\
\text { radar (CPR) } \\
94.05 \mathrm{GHz}\end{array}$ & $\begin{array}{l}\text { 2.5-m antenna. Nadir pointing. } 0.095^{\circ} \text { ( } 3 \mathrm{~dB} \text { ) beam width; } \\
660-\mathrm{m} \text { ground footprint. Extended Interaction Klystron (EIK), } \\
3.3-\mu \text { s pulses. Pulse repetition frequency } 6100-7500 \mathrm{~Hz} \text {. } \\
\text { Doppler capability. } 500-\mathrm{m} \text { vertical resolution, oversampled at } \\
100 \mathrm{~m} \text { down to I km below the surface. Horizontal sampling } \\
500 \mathrm{~m} \text {. }\end{array}$ & $\begin{array}{l}\text { Cloud and vertical motion products. } \\
\text { Synergy with ATLID and MSI: narrow } \\
\text { swath profiles of liquid and ice-cloud } \\
\text { content and extinction, particle size } \\
\text { and concentration, and precipitation } \\
\text { rates (all with uncertainties). }\end{array}$ \\
\hline $\begin{array}{l}\text { Multispectral } \\
\text { imager (MSI) }\end{array}$ & $\begin{array}{l}\text { Nadir pushbroom imager with seven channels: } 0.670,0.865 \text {, } \\
\mathrm{I} .65,2.21,8.80,10.80 \text {, and } 12.00 \mu \mathrm{m} \text {. To reduce sunglint the } \\
\text { swath is tilted to right of ground track looking forward } \\
\text { along the orbit, so it is } 115 \mathrm{~km} \text { to the right, } 35 \mathrm{~km} \text { to the left. } \\
\text { Sampling } 500 \mathrm{~m} \times 500 \mathrm{~m} \text { at nadir. }\end{array}$ & $\begin{array}{l}\text { Cloud and aerosol products. Radiances } \\
\text { used to construct 3D cloud-aerosol } \\
\text { scenes around narrow swath of } \\
\text { retrieved profiles, leading to estimates } \\
\text { of radiative flux and heating rate } \\
\text { profiles. }\end{array}$ \\
\hline $\begin{array}{l}\text { Broadband } \\
\text { radiometer (BBR) }\end{array}$ & $\begin{array}{l}\text { Channels: } 0.25-50 \mu \mathrm{m}, 0.25-4 \mu \mathrm{m} \text {; three fixed telescopes: } \\
\text { nadir, forward, and backward (at } 50^{\circ} \text { viewing zenith } \\
\text { angles). Radiometric accuracy: } \mathrm{SW} 2.5 \mathrm{~W} \mathrm{~m} \mathrm{~m}^{-2} \mathrm{sr}^{-1} ; \mathrm{LW} \\
\mathrm{I} .5 \mathrm{~W} \mathrm{~m} \mathrm{~m}^{-2} \mathrm{sr}^{-1} \text {. Mean radiances averaged to } 10 \mathrm{~km} \times 10 \mathrm{~km} \\
\text { will be oversampled and reported every } \sim 1 \mathrm{~km} \text { along track. }\end{array}$ & $\begin{array}{l}\text { Observed solar and thermal radiances } \\
\text { and their derived fluxes are compared } \\
\text { with those predicted by radiative } \\
\text { transfer models applied to 3D } \\
\text { constructed scenes. }\end{array}$ \\
\hline
\end{tabular}

clouds and aerosols from the molecular return, thus providing a direct measurement of the extinction profile of clouds and aerosols and, when combined with the cross-polar return, better identification of aerosol type and ice particle characteristics. The EarthCARE cloud profiling radar (CPR) will have a Doppler capability and so give information on convective motions as well as ice and rain fall speeds, leading to improved drizzle, rainfall, and snowfall rates. The additional $7 \mathrm{~dB}$ of sensitivity (a factor of 5) compared with CloudSat will enable it to better detect thin ice clouds and much more low-level stratus and stratocumulus. The radar and lidar signals will be combined with observations from the multispectral imager (MSI) within an optimal-estimation framework to give a detailed 2D profile of the properties of the clouds and aerosol. The information from the broader swath of the MSI will be used to extend the 2D profiles into a full 3D domain; this 3D domain will be used as input to broadband radiative transfer models so that fluxes, heating rates, and radiances may be computed and TOA radiances and fluxes compared to those derived from EarthCARE's broadband radiometer (BBR). Simulations described in this paper suggest that it will be possible to compute TOA fluxes and compare them with the BBR observations over each $10 \mathrm{~km} \times 10 \mathrm{~km}$ scene to an accuracy of $10 \mathrm{~W} \mathrm{~m}^{-2}$. The comparison between the modeled and observed BBR observations will provide a unique and useful consistency evaluation of the retrievals that will be used to help evaluate and improve EarthCARE products.

These data will be invaluable for studying cloud, aerosol, precipitation, and radiation processes and how they vary on a seasonal and regional scale. Comparison of the observations with climate and weather models will enable the testing of the various parameterization schemes, such as ice particle fall speed, ice particle size distributions, ice mass versus size, and autoconversion of liquid water to rain. This can be done at a statistical level by comparing climate models with observations and seeing how well the mean properties and the probability distribution functions of the cloud, aerosol, precipitation, and radiation variables, together with their geographical and seasonal changes, are captured by the models. For weather models and climate models run in forecast mode, individual scenes can be compared at $10 \mathrm{~km} \times 10 \mathrm{~km}$ resolution. To enable EarthCARE data to be assimilated into forecast models, it is expected that nominal level 1 (L1) data will be available within 


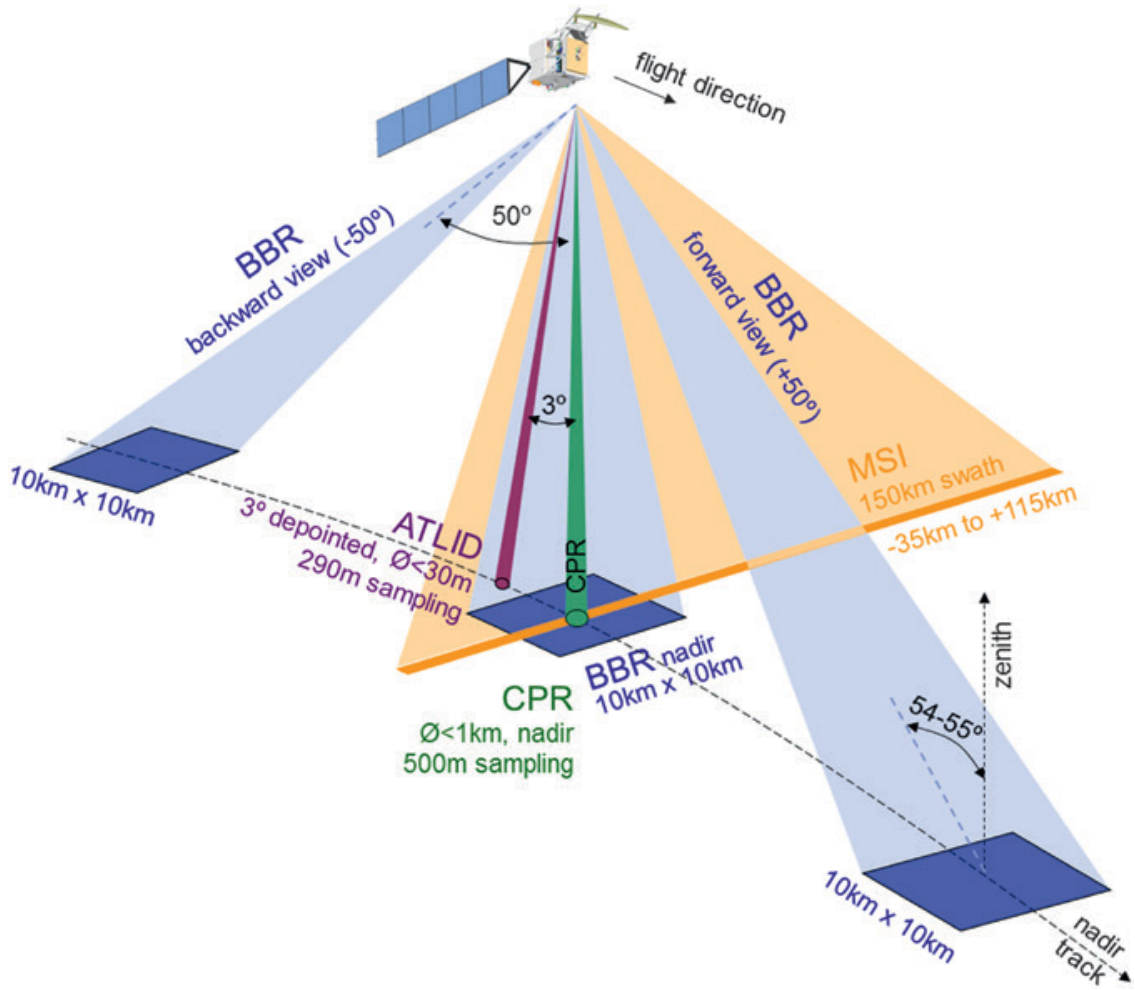

FIG. 3. Viewing geometry and sampling of the four instruments on the EarthCARE, which will fly in a sun-synchronous $97^{\circ}$ inclination orbit at $393-\mathrm{km}$ height with mean equator local descending node crossing time of $1400 \mathrm{~h}$ and a 25-day repeat cycle.

$5.5 \mathrm{~h} 60 \%$ of the time. For worst-case blind orbits, data should be available within $24 \mathrm{~h}$ for single-instrument (L2a) and $48 \mathrm{~h}$ for synergistic (L2b) products.

Figure 4 shows the multilevel structure of EarthCARE's geophysical products (L2). To optimally exploit the synergy between the various instruments, provide tolerance to the possibility of instrument degradation or failure, and to maintain continuity with established retrieval methods, an integrated combination of single-instrument (L2a) and multiinstrument (L2b) retrievals is being implemented. Many of the algorithms require estimates of the vertical profiles of temperature, pressure, and humidity, which will be provided by the European Centre for MediumRange Weather Forecasts. In the next sections we consider the specification and retrieval algorithms of the four individual instruments. This is followed by discussion of synergistic retrievals using a combination of instruments.

94-GHz cloud profiling radar. EarthCARE will have the first atmospheric radar in space with Doppler capability. Because of its larger antenna and lower orbit, it will have 7-dB higher sensitivity compared with CloudSat. The CPR antenna is shown in Fig. 5.
Estimating Doppler velocities from space is difficult (see related sidebar "Challenges in measuring Doppler velocity from space") because of satellite motion, velocity folding, and nonuniform beam filling (NUBF). CloudSat is calibrated by periodically pointing the beam $11^{\circ}$ across track and measuring the (known) sea surface return; EarthCARE CPR calibration will be slightly different, involving a periodic $10^{\circ}$ sweep across track. In addition, as for CloudSat, the precise antenna beam pattern and radiometric performance will be evaluated by placing active radar calibrators (ARCs) within the footprint of the CPR as it overflies Japan (Horie et al. 2012). In addition to using the ARCs to validate the CPR antenna pointing, simulations (Battaglia and Kollias 2014) have shown that Doppler returns from natural targets, such as high cirrus clouds over the length of an orbit, can be used to estimate the accuracy of the pointing bias of the antenna and reduce its impact on the Doppler uncertainty.

A pulse-pair method will be used for the Doppler measurements using the phase shift between echo signals from successive pulses; however, velocity ambiguities arise when this phase shift exceeds $\pm 180^{\circ}$. With a pulse repetition frequency (PRF) of $7.5 \mathrm{kHz}$ (pulse separation $20 \mathrm{~km}$ ) this leads to a folding velocity of $6 \mathrm{~m} \mathrm{~s}^{-1}$. The motion of the satellite induces a $3.8 \mathrm{~m} \mathrm{~s}^{-1}$ Doppler width in the target return; the lower this Doppler width is compared with the folding velocity, the more accurate is the retrieved Doppler velocity. Accordingly, the highest possible PRF is chosen compatible with the pulse separation being less than the cloud depth, and a variable PRF is adopted with range windows of 20,16 , or $12 \mathrm{~km}$ depending on the latitude.

An example of correction algorithms using the high-resolution observations from the $94-\mathrm{GHz}$ Atmospheric Radiation Measurement Program (ARM) cloud radar during its deployment in the 
Black Forest, Germany $\left(48^{\circ} 32^{\prime} 24^{\prime \prime} \mathrm{N}, 8^{\circ} 23^{\prime} 49^{\prime \prime} \mathrm{E}\right)$, is displayed in Fig. 6 . The biases introduced by the NUBF within the EarthCARE CPR footprint can be estimated (Tanelli et al. 2002; Sy et al. 2014) and are displayed in Fig. 6b. The simulated, uncorrected EarthCARE Doppler velocities at 1-km integration are shown in Fig. $6 \mathrm{c}$ where the noisy Doppler velocities in regions with radar reflectivities below $-20 \mathrm{dBZ}$ have been suppressed (Kollias et al. 2013).
The NUBF biases are easy to detect near cloud edges and in areas with strong horizontal reflectivity gradients. CPR velocity folding is noticeable in liquid precipitation (e.g., at ranges between 200 and $250 \mathrm{~km}$ ). Furthermore, the CPR velocity field is noisier than the ARM Doppler velocity field owing to the Doppler fading effect arising from satellite motion.

Figure $6 \mathrm{~d}$ displays the results of using the $500-\mathrm{m}$ integrated reflectivities simulated for the EarthCARE

\section{CHALLENGES IN MEASURING DOPPLER VELOCITIES}

\section{FROM SPACE}

- Schematic representation (Fig. SBI) of the challenges due to the satellite motion, backscatter signal strength, NUBF, and velocity folding (when phase shifts exceed $\left.180^{\circ}\right)$ associated with Doppler measurements from space.

- The shading of the CPR sampling volume indicates the strength of the backscattered signal.

- The vertical arrows indicate the apparent velocity introduced to the CPR volume due to the motion of the satellite (pink toward and blue away from the satellite).

- Green areas: Doppler spectra that would be observed by a motionless platform with no velocity folding.

- Purple areas: Doppler spectra broadened by $3.8 \mathrm{~m} \mathrm{~s}^{-1}$ due to satellite motion.

- Horizontal red arrows: expected velocity error for the CPR.

- Vertical red lines: the apparent velocity bias introduced by satellite motion.

I) Uniform weak echo filling the beam; true Doppler velocity zero. The CPR velocity is unbiased, but with a large CPR error because of the poor signal-to-noise ratio.

2) Strong uniform echo; true Doppler velocity zero. The CPR velocity is unbiased with a much smaller error because of the higher signal-to-noise ratio.

3) Strong nonuniform echo; true Doppler velocity is zero. NUBF biases the CPR velocity. The bias may be corrected if the reflectivity gradient across the beam is known.

4) Return to a uniform echo, but with the true velocity outside the Nyquist frequency. The CPR mean velocity is folded.

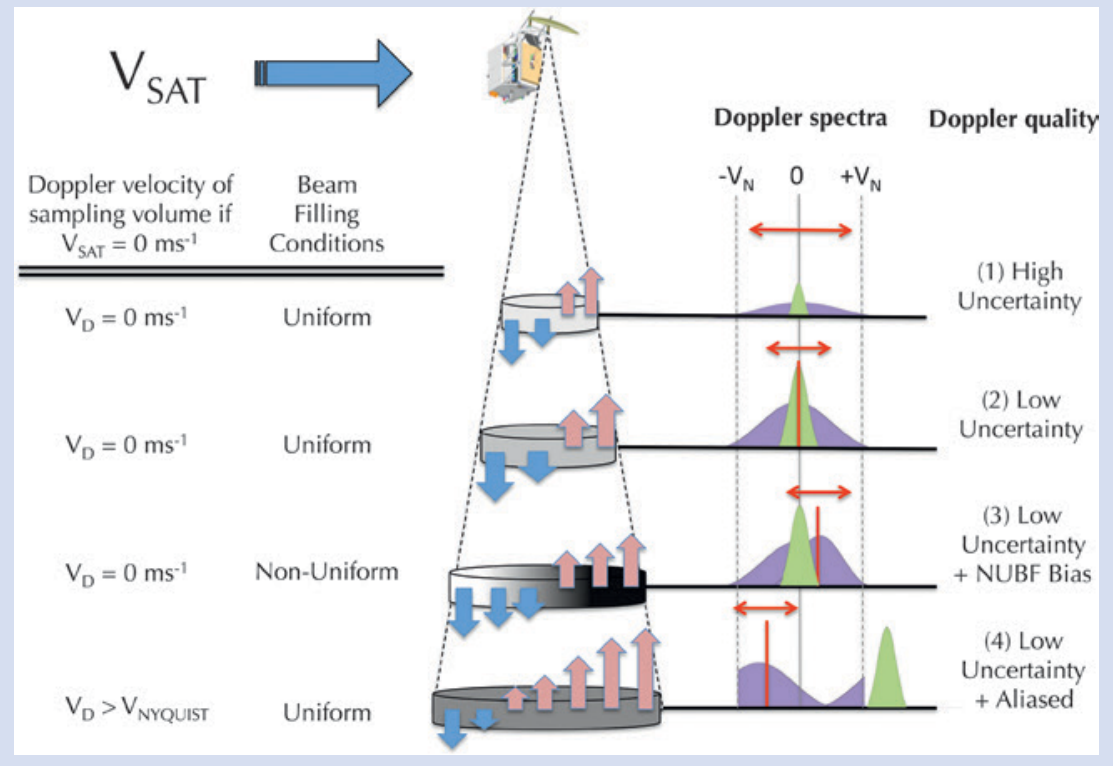

CPR and applies a NUBF correction [of order $0.2 \mathrm{~m} \mathrm{~s}^{-1}(\mathrm{dBZ} \mathrm{km})^{-1}$ in magnitude] based on the gradient of reflectivity across the 1-km footprint. Velocity unfolding is also performed using velocity continuity in the low levels. In areas with high signalto-noise ratio the simulated $\mathrm{CPR}$ velocity uncertainty is below $0.5 \mathrm{~m} \mathrm{~s}^{-1}$ Retrievals in vigorously convective regions will be much more challenging. Further details of Doppler velocity correction techniques can be found in Schutgens (2008) and Sy et al. (2014).

The CPR cloud mask algorithm, based on Doppler cloud radar data from the Research Vessel Mirai (Okamoto et al. 2007, 2008) and CloudSat (Hagihara et al. 2010), uses signal-tonoise ratio and spatial continuity to identify clouds. Classification into cloud particle types utilizes vertical structures of reflectivity, Doppler velocity, and temperature to identify threedimensional ice (3D), horizontally oriented ice (2D), liquid water, the melting layer, snow, and rain. Icescattering properties and reflectivity-weighted terminal velocity are estimated in terms of shape, orientation, and size by the discrete dipole approximation (Sato 
et al. 2009) to retrieve the following properties: effective radius, ice and liquid-water content, snow and rain rate and their amount, sedimentation velocity, and vertical air motion (Sato et al. 2009; Sato and Okamoto 2011).

355-nm high-spectralresolution lidar. The EarthCARE atmospheric lidar (ATLID) is a linearly polarized HSRL (Shipley et al. 1983) transmitting a spectrally narrow laser line at $355 \mathrm{~nm}$ and separating the backscatter return into three channels: a "Mie" channel, receiving the copolar return from clouds and aerosols; a copolar "Rayleigh" channel, receiving copolar backscatter from atmospheric molecules; and a channel receiving the total backscattered crosspolar signal.

In the absence of any attenuating cloud or aerosol, the profile of the Rayleigh channel is defined by the known profile of air density. The extinction profile of the clouds and aerosols can be derived from the observed reduction in the Rayleigh profile below this expected value. This extinction profile may then be used to correct the observed attenuated Mie backscatter profile, and the true "lidar" or "extinction-tobackscatter" ratio $(S)$ may be calculated (see "Optical depth from the HSRL" sidebar and the associated figure). In contrast, a simple elastic backscatter lidar like CALIOP must assume a value for $S$ in order to estimate the extinction coefficient (Omar et al. 2009) or, in the case of isolated layers embedded in clear air, constrained retrievals using molecular scattering below and above the layer as a reference are applied (Young and Vaughan 2009).

The nighttime copolar Mie-channel performance of ATLID should be similar to the 532-nm CALIOP channel, but better daytime sensitivity is expected because of reduced background noise due to the smaller field of view, the narrower

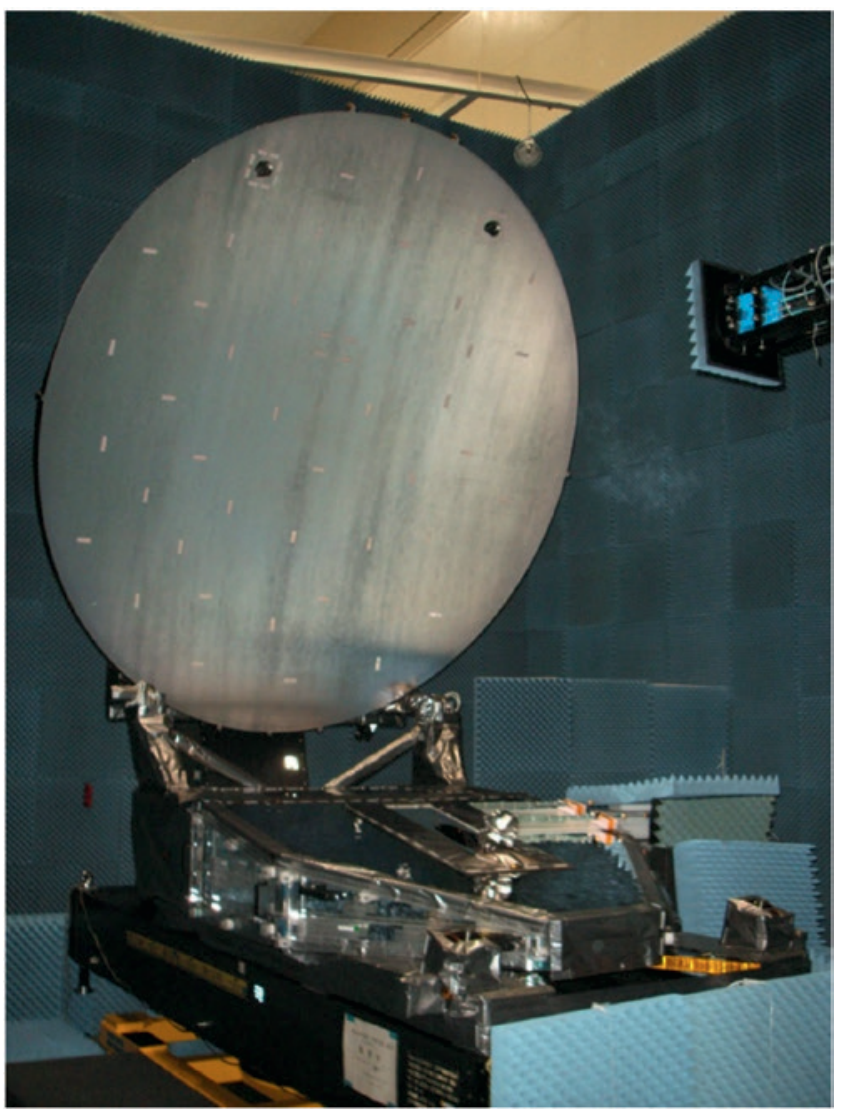

Fig. 5. The 2.5-m antenna for the $94-\mathrm{GHz}$ radar. 
$0.3 \mathrm{~nm}$ filter, and the lower levels of earthshine than at $532 \mathrm{~nm}$. Absolute calibration of the Rayleigh channel will be achieved by long integrations (e.g., $500 \mathrm{~km}$ horizontal) of the molecular returns between 35- and 40-km height. Cross-talk leakage between the Rayleigh and Mie channels will be determined by hardware-based onboard spectral calibration so that the Mie channel can be calibrated via the leaked Rayleigh signal. More details on the technical specifications of ATLID can be found in Durand et al. (2007).

Figure 7 gives an indication of the expected performance of the ATLID HSRL for retrieving aerosol extinction and backscatter profiles compared with a 532-nm CALIPSO-type retrieval. This example is based on a simulated aerosol field from the Deutscher Wetterdienst (DWD)-Consortium for Small-Scale Modeling (COSMO) model, used as input to the lidar component of the EarthCARE simulator (ECSIM) (Voors et al. 2007). The simulations include the effects of instrument noise and, for ATLID, cross talk between the Rayleigh and Mie channels. The profiles obtained by running retrieval algorithms on the simulated signals for a 50-km horizontal distance are displayed in Fig. 7, highlighting the superior performance of the HSRL technique over the backscatter lidar approach when the aerosol layer extends down to the surface. Here, the uncertainty in the CALIPSO retrieval is mainly due to the range of assumed values of $S$ used in the retrieval procedure $(65 \pm 20 \mathrm{sr}$ at $532 \mathrm{~nm}$ ). Using the wrong value of $S$ will, in effect, lead to the wrong extinction correction being used to estimate the true backscatter profile from the observed attenuated backscatter profile. In the present case, a $30 \%$ uncertainty in $S$ leads to a $30 \%$ overcorrection of the two-way attenuation in the observed backscatter signal and a further 30\% error, making $60 \%$ in total, when $S$ is used 
together with the estimated backscatter profile to calculate the total layer optical thickness. The errors in the retrieved profile due to an error in the specified value of $S$ are strongly dependent on the two-way transmission to the layer top; thus, for larger optical depths, the profile errors propagating down from the layer top can be much higher than those shown here.

Clouds, in general, lead to higher attenuated backscatter and Rayleigh-channel attenuations than is the case for aerosols. Methods using the Mie and Rayleigh channel returns together within an optimalestimation framework are in advanced development and, apart from clouds such as tenuous cirrus, should deliver cloud products at the $1-\mathrm{km}$ horizontal scale. Cloud detection will be provided at scales down to the native resolution of $143 \mathrm{~m}$ for one shot or $285 \mathrm{~m}$ for two onboard summed shots.

Liquid-water and ice partitioning is one of the major sources of uncertainties in sensitivity studies of future climate (Watanabe et al. 2010). Discrimination between cloud, aerosol, and molecules may be achieved from HSRL data after noise reduction using wavelet analysis based on the technique of Okamoto et al. (2008). Yoshida et al. (2010) demonstrated how clouds may be classified from CALIOP depolarization and the extinction estimated using a forwardmodeling technique that includes multiple scattering and physical optics (Okamoto et al. 2010).

The quantification of direct aerosol radiative forcing in general and the achievement of radiative

\section{OPTICAL DEPTH FROM THE HSRI}

The problem of deriving optical depth from a backscatter lidar:

- A simple backscatter lidar provides only an attenuated backscatter profile.

- The extinction can only be derived by assuming a value of the lidar ratio (extinction-to-backscatter ratio).

- The lidar ratio for aerosols can vary between about 10 and $100 \mathrm{sr}$.

- Even though, on average, a priori assignments of lidar ratio may be better than $20 \%-50 \%$. Uncertain a priori estimates of the lidar ratio still may result in an error of the optical depth of a cloud or aerosol layer of a factor of 2.

The solution using a high-spectral-resolution lidar:

I) The backscatter return (red) consists of a broadband

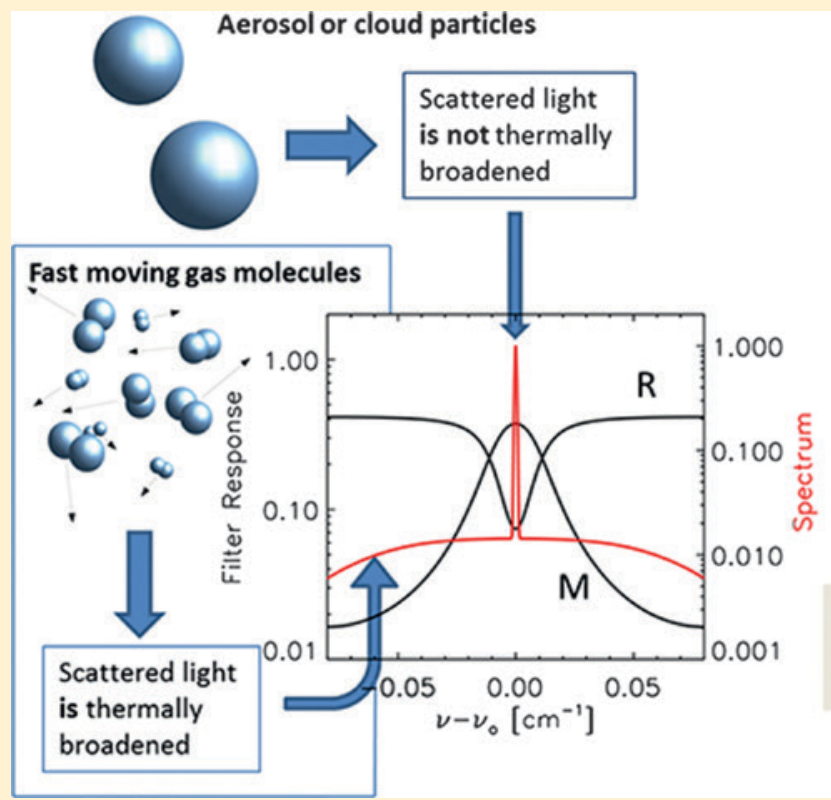

"Rayleigh" component from the rapidly moving molecules and a narrowband "Mie" return from the slower moving larger cloud and aerosol particles (left side of Fig. SB2).

2) The Rayleigh and Mie return are separated by two filters (black curves: $R$ and $M$ in left side of Fig. SB2).

3) Right-hand side of Fig. SB2 shows the Mie signal from a cloud or aerosol layer; coincident with this layer, the Rayleigh signal drops below the value predicted from the air density by an amount depending upon the optical depth of the layer.

4) Once the extinction profile is derived from the Rayleigh signal, then the Mie channel can be corrected for this attenuation and the lidar ratio derived from the ratio of the extinction profile to the attenuationcorrected backscatter profile.

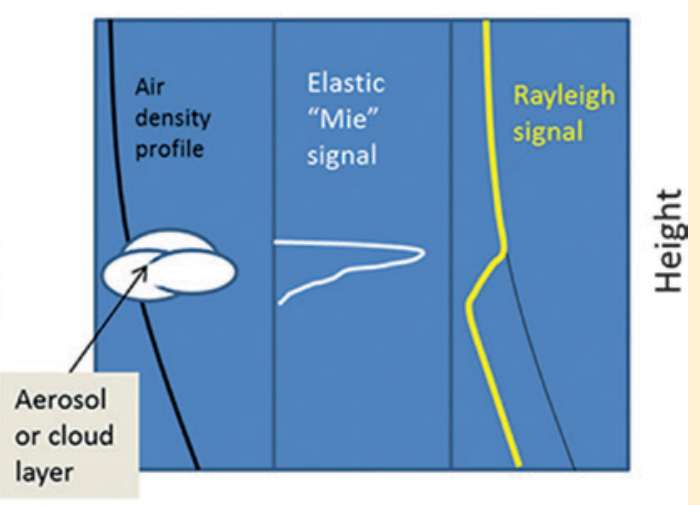


closure from EarthCARE observation in particular rely on a proper aerosol classification. Radiative transfer calculations require knowledge of particle size and absorption properties (single-scattering albedo) for shortwave solar radiation. Such information can be inferred if the aerosol is categorized into predefined aerosol types (Oikawa et al. 2013). Aerosol typing is also required for assimilation purposes and the validation of atmospheric transport models, which carry components like dust, sea salt, smoke, and pollution (sulfates). In general, typing can constitute the basis for the separation of anthropogenic and natural atmospheric impacts.

An aerosol typing scheme based on level 1 and auxiliary data was developed for CALIPSO with the primary goal of selecting correct lidar ratios for level 2 retrievals (Omar et al. 2009). This scheme has been widely used also in a broader scientific context (e.g., Amiridis et al. 2013; Oikawa et al. 2013). EarthCARE will provide a level 2 aerosol-type
Backscatter (BSC)

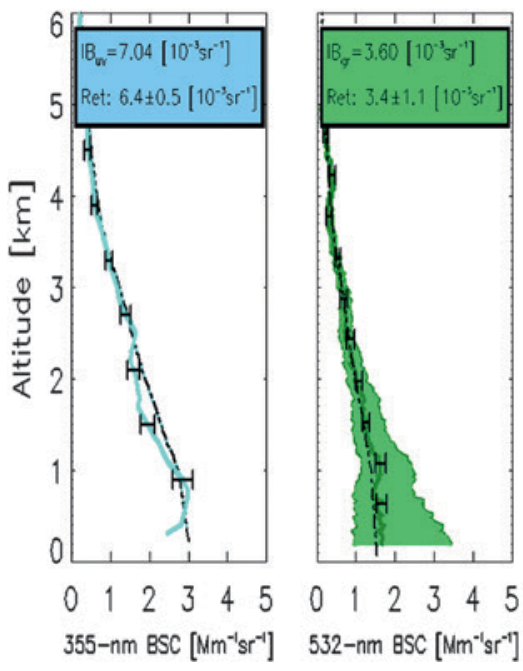

product that is mainly based on measured intensive (i.e., concentration independent) particle properties (e.g., Müller et al. 2007; Burton et al. 2012). This aerosol classification uses the measurements in Fig. 8 of lidar ratio and particle linear depolarization ratio at the ATLID wavelength of $355 \mathrm{~nm}$ to distinguish between 1) smoke plumes or anthropogenic pollution; 2) spherical, nonabsorbing marine aerosol; and 3) dust and volcanic ash. Intermediate values of lidar ratio and depolarization ratio may allow some estimate of the mixing state. Additional information such as geographical location, season, vertical distribution, and temperature as well as column-integrated Ångström exponents derived from combined ATLID $(355 \mathrm{~nm})$ and MSI $(670 \mathrm{~nm})$ optical depth retrievals will be used to refine the classification. In addition, the extinction from mixtures of aerosol components, such as black carbon, dust, and water-soluble aerosols, will be retrieved from the ATLID databased on the HSRL algorithm of Nishizawa et al. (2008) and the technique to infer nonsphericity of dust (Nishizawa et al. 2011).
Extinction (EXT)

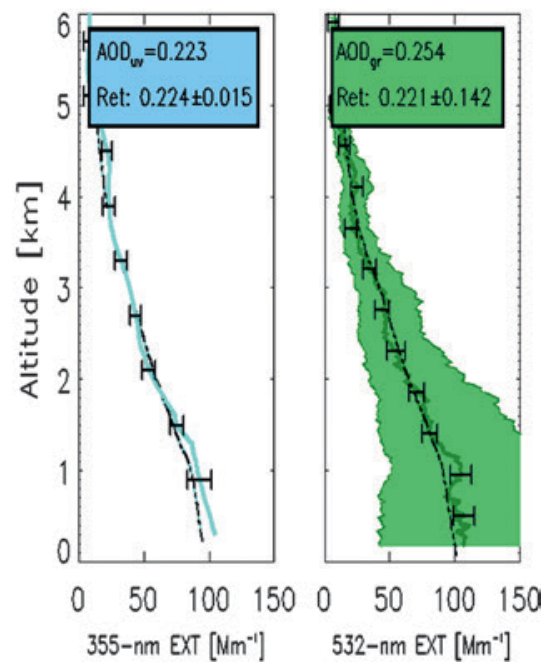

FIG. 7. Retrieval of backscatter and extinction profiles using simulated ATLID HSRL signals at $355 \mathrm{~nm}$ (blue) compared with the profiles retrieved with corresponding simulated CALIOP signals at $532 \mathrm{~nm}$ (green). A simulated sulfate aerosol field was used with an effective radius of $0.5 \mu \mathrm{m}$ so that the aerosol optical depth is 0.233 at $355 \mathrm{~nm}$ with the lidar ratio $(S)$ equal to $35 \mathrm{sr}$, and 0.254 at $532 \mathrm{~nm}$ with $S=65 \mathrm{sr}$. ECSIM was used to simulate the signals corresponding to a $\mathbf{5 0}-\mathbf{k m}$ horizontal integration for the ATLID Rayleigh and Mie channels and the $532-\mathrm{nm}$ channel of CALIOP. The lines are obtained by running corresponding HSRL and 532-nm backscatter retrieval algorithms on the simulated lidar signals. The black lines are the "true" profiles; the blue and green lines are the retrieved profiles. The spread in the green $(532 \mathrm{~nm})$ retrievals is due to the choice of $S$ from 45 to $85 \mathrm{sr}$ while the error bars show the smaller uncertainty due to random noise effects. Note that the HSRL errors for the inferred layer optical thickness and integrated backscatter (IB) are $8 \%$ and $7 \%$, respectively, but for the backscatter lidar they are $64 \%$ and $42 \%$
Multispectral imager. The MSI (Pérez Albiñana et al. 2010) will measure emitted infrared and reflected solar radiances. The spectral characteristics of the channels (Table 1) are comparable to Spinning Enhanced Visible and Infrared Imager (SEVIRI) (Meteosat) and Advanced Very High Resolution Radiometer (AVHRR) [National Oceanic and Atmospheric Administration (NOAA)] channels. The MSI comprises two separate optiand one for the thermal infrared (TIR) channels. Solar-channel calibration will be performed by dark-target measurements during eclipse of the orbit and sun calibration by looking directly to the sun during passes over the South Pole region. TIRchannel calibration uses the onboard blackbody source cal units: one for the solar 


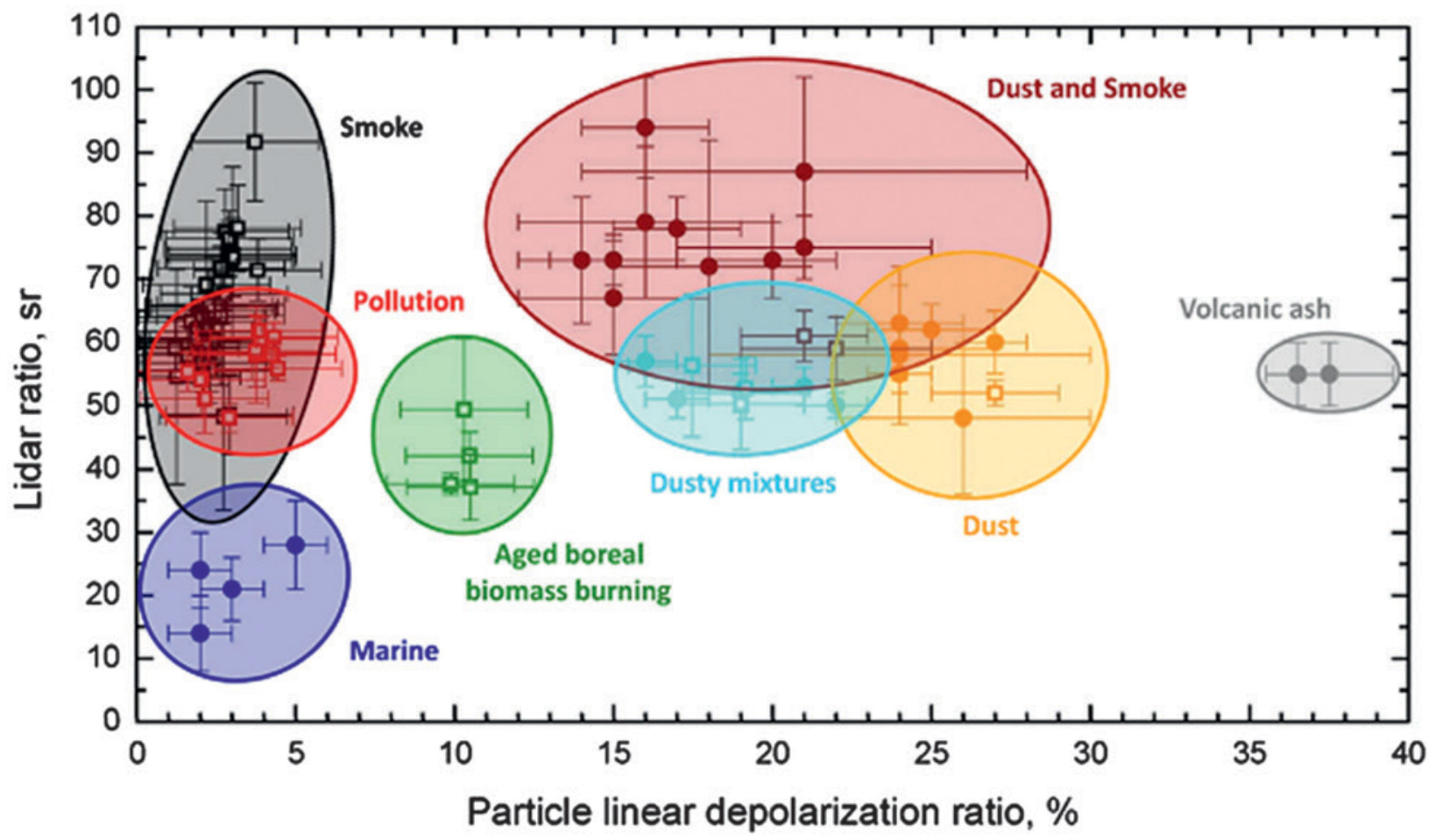

FIG. 8. Aerosol classification from measurements of lidar ratio and particle linear depolarization ratio at $355 \mathrm{~nm}$. Ground-based observations were performed with the Raman-polarization lidars (POLIS) (University of Munich, dots) and Polly ${ }^{\mathrm{T}}$ (Leibniz Institute for Tropospheric Research, open squares) at Cape Verde (dust, marine, dust and smoke, dusty mixtures; dots; Groß et al. 20II); Leipzig, Germany (pollution, aged boreal biomassburning aerosol, dusty mixtures; open squares); Munich, Germany (volcanic ash; dots; Groß et al. 20I2); in the Amazon basin (smoke; open squares; Baars et al. 20I2); and over the North Atlantic (dust, dust and smoke; open squares; Kanitz et al. 2013).

and the cold-space viewport. Radiometric performance in the visible and near-infrared channels is specified as a signal-to-noise ratio of about 70 for dim scenes and 500 for bright scenes, and about 20 and 250 , respectively, for these scenes in the shortwave infrared. Noise requirement for the TIR channels is $0.80 \mathrm{~K}$ for cold $(220 \mathrm{~K})$ and $0.25 \mathrm{~K}$ for warm $(293 \mathrm{~K})$ scenes. Long-term radiometric stability over one year is anticipated to be better than $1 \%$ for solar channels and $0.3 \mathrm{~K}$ for TIR channels.

MSI data will be used to 1) infer column-integrated aerosol and cloud properties, 2) constrain synergistic retrievals, and 3) construct small 3D atmospheres around the $2 \mathrm{D}$ cross section retrieved from the radar and lidar. In the first step of the data analysis, cloudscreening algorithms establish each pixel as cloudy or clear and determine the cloud thermodynamic phase by applying static and dynamic threshold tests to radiances (Ishida and Nakajima 2009). In the second step, all MSI pixels are analyzed to retrieve aerosol optical depth, aerosol Ångström exponent, cloud optical depth, effective particle radius, cloud-top temperature, and pressure. Aerosol optical depth is retrieved at $0.6 \mu \mathrm{m}$ over ocean and land as well as at $0.8 \mu \mathrm{m}$ over ocean (Higurashi et al. 2000; von HoyningenHuene et al. 2003). Cloud microphysical retrievals are based on the combination of visible channels $(0.6 \mu \mathrm{m}, 0.8 \mu \mathrm{m})$ and near-infrared channels $(1.6 \mu \mathrm{m}$, $2.2 \mu \mathrm{m})$. Cloud-top height retrieval is limited to infrared-window channels, but an improved estimate along the lidar track can be obtained via synergy with ATLID. Additionally synergistic analysis using CPR, ATLID, and MSI measurements have been developed using data from CloudSat, CALIOP, and MODIS (e.g., Nakajima et al. 2010; Suzuki et al. 2010).

Multiangle broadband radiometer. The BBR will measure TOA reflected solar and emitted thermal radiances in three viewing directions (Fig. 3, Table 1) with a time delay of $\sim 150 \mathrm{~s}$ between forward and backward views of a surface target. The swath is sufficiently wide so that the three views align along the satellite track, yielding excellent characterizations of the surface-atmosphere anisotropy. The BBR telescopes measure total-wave radiances from $0.25 \mu \mathrm{m}$ to beyond $50 \mu \mathrm{m}$. Applying an uncoated synthetic quartz filter 
mounted on a rotating drum to each telescope results in the shortwave (SW) channel covering $0.25-4.0 \mu \mathrm{m}$. Longwave (LW) radiances are obtained by differencing the two channels. To remove instrumental spectral response effects, measured radiances are "unfiltered," thus isolating estimates of actual SW and LW radiances (Velázquez-Blázquez and Clerbaux 2010). Radiometric calibration will be performed using onboard hot and cold black bodies. Aging effects on the SW channel will be monitored with a solar calibration unit (Proulx et al. 2010).

TOA flux estimates, to be used for radiative closure assessment, are derived by applying angular distribution models (ADMs) to the three BBR radiances collocated at a reference height. Fluxes for each view are used for an internal consistency check and combined into a single flux for each $(10 \mathrm{~km})^{2}$ scene. EarthCARE's SW scene type-dependent ADMs were constructed from CERES and MODIS data using a feed-forward back-propagation artificial neural network (Domenech and Wehr 2011) and assessed via comparison to CERES ADMs (Loeb et al. 2005). Inputs are BBR SW radiance, angular geometry, weighted MSI radiances surface descriptors, and cloud fraction inferred from MSI. LW ADMs are based on correlations between the anisotropy of BBR radiances and spectral information provided by MSI LW radiances (Clerbaux et al. 2003; Domenech et al. 2011). Anisotropic factors were estimated through multiple regressions on simulated MSI brightness temperatures and corresponding LW fluxes computed by a $1 \mathrm{D}$ radiative transfer model.

SYNERGY ALGORITHMS. A notable successful application of sensor synergy is provided by the development and deployment of combined lidar and cloud radar algorithms for the retrieval of cloud macro- and microphysics (e.g., Donovan et al. 2001). Lidars are sensitive to small cloud/aerosol particles, but lidar signals can often be strongly attenuated by clouds. Cloud profiling radars are not strongly attenuated by clouds but are not sensitive to small cloud particles and can miss some low-level water clouds and optically thin cirrus. The combination of lidar and radar not only provides a much more complete height-resolved detection of the presence of clouds but can also provide quantitative information on the cloud particle size and water content by exploiting the different response to particle size between the two wavelengths (Okamoto et al. 2003, 2010). The lidar and radar synergy within EarthCARE also incorporates the data streams from the MSI in order both to improve the cloud and aerosol profile retrievals (e.g., Delanoë and Hogan 2010) and to provide a $2 \mathrm{D}$ horizontal context to the retrieved nadir profiles (Barker et al. 2011). The data processing chain of EarthCARE is being designed with sensor synergy as a guiding principle from the ground up. This will enable effective use of the total EarthCARE instrument package. In the remainder of this section we present some illustrative examples of the types of synergistic algorithm that will be employed in the EarthCARE processing scheme.

Target classification. Before microphysical retrieval algorithms can be applied, it is necessary to report the lidar and radar data on a common joint standard grid and to apply cloud/aerosol mask schemes (Hagihara et al. 2010) that identify particle types present at each point in the grid (Yoshida et al. 2010; Nishizawa et al. 2008). The possible radar targets are liquid-cloud droplets, ice particles, raindrops, aerosols, insects, and stratospheric particles (which may be aerosols or clouds). Combinations are possible (e.g., in mixedphase clouds where supercooled liquid droplets coexist with ice particles). This approach builds on work to combine radar-only and lidar-only cloud masks (e.g., Hagihara et al. 2010).

Illingworth et al. (2007) made extensive use of target classification in the "CloudNET" processing of ground-based radar and lidar data, and this approach has since been applied to CloudSat and CALIPSO (Delanoë and Hogan 2010; Ceccaldi et al. 2013). The classification to be applied to EarthCARE borrows heavily from this work. Essentially, when the radar observes a signal it is interpreted as ice if above the melting layer (determined from the wetbulb temperature in the model and the radar Doppler velocity) and rain if below. Relatively strong lidar echoes are interpreted as liquid clouds, while weaker ones are interpreted as aerosols, thin ice clouds, or stratospheric particles, depending on their height. Supercooled water can be distinguished from ice using a combination of lidar backscatter and depolarization (Yoshida et al. 2010).

Synergistic cloud, aerosol, and precipitation retrievals. EarthCARE will deploy two synergistic algorithms for cloud microphysics. The first builds on the ice-cloud retrievals of Okamoto et al. (2010) and Sato and Okamoto (2011) that have been applied to CloudSat and CALIOP using optimal-estimation theory to provide a rigorous estimate of retrieval uncertainties. The basic structure of the earlier version of the synergy algorithms (Okamoto et al. 2003) was adopted in the operational CloudSat and 
CALIPSO synergy algorithm to produce the CloudSat 2C-ICE standard product (Deng et al. 2010). The algorithm will utilize all radar and lidar variables to reliably retrieve water content and effective radius of liquid and ice clouds, rain, and snowfall rate, as well as information on the concentration of planar ice particles. The technique of Sato et al. (2009) will be used to split the measured Doppler velocity into air motion and terminal fall-speed components.

A second "unified" algorithm, CAPTIVATE, combines the radar, lidar, and also the imager to retrieve the microphysical properties of cloud, aerosol, and precipitation simultaneously. Frequently, multiple particle types are present in the profile (e.g., liquid cloud beneath ice cloud), and CAPTIVATE is unique in being able to exploit solar radiances in this situation, which are dependent on the optical depth of all particles in the profile. Each profile is processed in turn, and the first step is to use the target classification to decide what "state variables" to retrieve that describe the properties of the particles at each vertical level. These are then used in a "forward model" that simulates the radar, lidar, and imager observations. Radar and lidar multiple scattering is accounted for using the models described by Hogan (2008). Optimal-estimation theory is used. A "cost function" is defined that penalizes differences between the observations and the corresponding forward-modeled values and between the state variables and their a priori estimates. The CAPTIVATE algorithm then finds the set of state variables that minimizes the cost function.

The ice-cloud/snow component of the CAPTIVATE algorithm inherits directly from the CloudSat-CALIOP-MODIS algorithm of Delanoë and Hogan (2010) but exploits the additional Doppler information. The liquid-cloud component retrieves liquid-water content at each height, with a "gradient constraint" added to the cost function to prevent a superadiabatic increase with height and a constraint on the total amount of liquid in the column available from the radar path-integrated attenuation (PIA) over the ocean (e.g., Lebsock et al. 2011). The rain component automatically makes use of the gradient of radar reflectivity with height to infer rain rate (Matrosov 2007) and over the ocean will also use the PIA (L'Ecuyer and Stephens 2002). An ambiguity can arise at $94 \mathrm{GHz}$ when a reflectivity profile with values reducing toward the ground can be caused either by evaporating drizzle or by heavier rain attenuating the signal. In simulations, however, we have found that this can be resolved because the Doppler velocity would differ by around $2 \mathrm{~m} \mathrm{~s}^{-1}$. More accurate snowfall rates can be derived using the Doppler velocity to infer the degree of riming. The aerosol component uses the HSRL molecular return to estimate the extinction profile but with a smoothness constraint in height and a Kalman smoother horizontally to cope with the noisiness of the signal. The expected effective horizontal resolution of the aerosol retrieval is $10-50 \mathrm{~km}$, depending on the optical depth.

The performance of the A-Train version of CAPTIVATE is illustrated in Fig. 9, which also includes a simulation of what the EarthCARE radar and lidar would measure for the same scene. The CloudSat and CALIOP signals are shown in Figs. 9a and $9 \mathrm{~b}$, with the target classification information from Ceccaldi et al. (2013) in Fig. 9c. These observations have been used in a retrieval of ice, liquid cloud, rain, and aerosols. The $0.5-\mu \mathrm{m}$ extinction coefficient of all four components combined is shown in Fig. 9d, along with its retrieval uncertainty in Fig. 9e. CAPTIVATE reports retrieval uncertainties in ice extinction of $10 \%-20 \%$ in the lidar-radar overlap regions but closer to $50 \%$ in the radar-only regions largely because of uncertainties in the ice-scattering model (Hogan and Westbrook 2014).

These CAPTIVATE retrievals have then been used to forward model what EarthCARE would see. First, Fig. 9 f depicts the EarthCARE radar reflectivity factor, and we can see immediately the effect of the 7-dB extra sensitivity. A large fraction of the high ice cloud seen only by CALIOP would be detected by the EarthCARE radar. In this case, for clouds above $10 \mathrm{~km}$ (colder than $-30^{\circ} \mathrm{C}$ ), CloudSat detected $66 \%$ of the clouds seen by the lidar and EarthCARE 97\%, but these figures are dependent on ice-scattering assumptions used to predict $Z$ in the lidar-only regions. Experience with CALIPSO is that lidar-only retrievals of cirrus optical depth are less accurate when the cloud is so thick that no below-cloud molecular signal is detected. While this will also be the case for EarthCARE, the effect is mitigated by 1) the shorter wavelength leading to a much stronger molecular signal and 2) the higher radar sensitivity meaning that cirrus thick enough to obscure the lidar molecular signal will invariably also be detectable to radar. Delanoë and Hogan (2010) have demonstrated that synergy algorithms exploiting the radar return and the cloud and molecular returns from the lidar can retrieve optical depth seamlessly and reliably in such situations.

Doppler velocity is a key new EarthCARE variable. The vertical wind is not known from the A-Train alone, so we can only simulate the Doppler velocity owing to fall speeds, and this is shown in Fig. $9 \mathrm{~h}$ using the Doppler multiple-scattering simulator of Battaglia 
and Tanelli (2011) and the corrections discussed in the context of Fig. $6 \mathrm{~d}$. For a $5-\mathrm{km}$ integration length we expect errors to be about $0.5 \mathrm{~m} \mathrm{~s}^{-1}$ in regions that are not highly convective. Finally, the signals that would be measured by the Mie and Rayleigh channels of the EarthCARE lidar are shown in Figs. 9g and 9i, respectively. These were simulated using the lidar component of ECSIM and include a rigorous Monte Carlo treatment of lidar multiple scattering as well as the effects of cross talk between channels and their simulated correction.

Figure 10 illustrates the CAPTIVATE algorithm for a single data profile from Fig. 9 containing rain and ice cloud (where the latter includes snow). The top two panels confirm that at the final iteration of the algorithm, the forward model very closely reproduces the observations. The importance of incorporating the effects of multiple scattering is highlighted by the fact that when multiple scattering is omitted from the forward model (red dashed lines), the radar and lidar signals are both underestimated. Figure $9 \mathrm{c}$ depicts the retrieved particle size, with retrieval uncertainty, and it can be seen that the uncertainty is smallest between 12 and $15 \mathrm{~km}$ where both the radar and lidar receive a good signal. Figure $9 \mathrm{~d}$ shows that the surface rain rate for this profile was around $5 \mathrm{~mm} \mathrm{~h}^{-1}$, and it is encouraging that precipitation flux is approximately conserved across the melting layer. Note that the strong surface return in Fig. 9a does not contaminate the rain-rate retrieval.

Radiation and closure assessment. Three broadband 1D radiative transfer models-CERES (Fu and Liou 1992), (a) CloudSat radar reflectivity factor (dBZ)

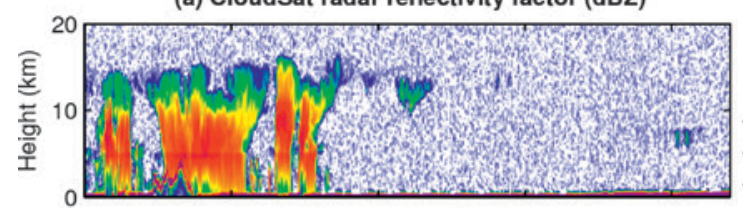

(c) Target classification

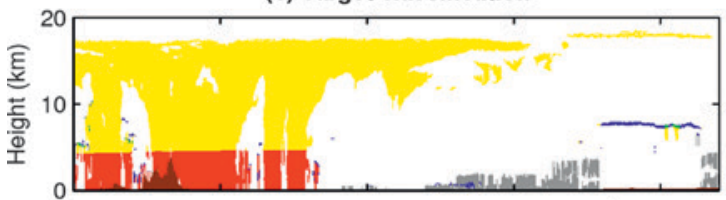

(d) Retrieved extinction coefficient $\left(\mathrm{m}^{-1}\right)$

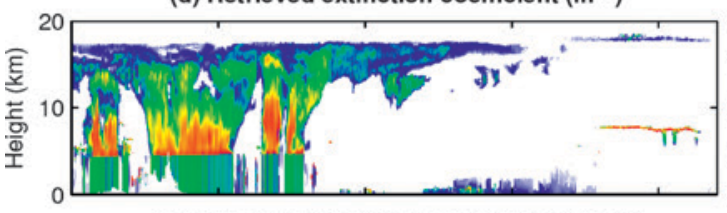

(f) EarthCARE radar reflectivity factor (dBZ)

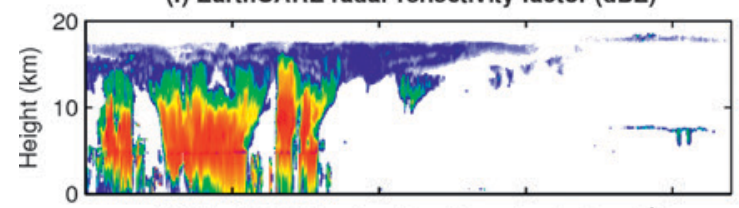

(h) EarthCARE radar Doppler velocity $\left(\mathrm{m} \mathrm{s}^{-1}\right)$

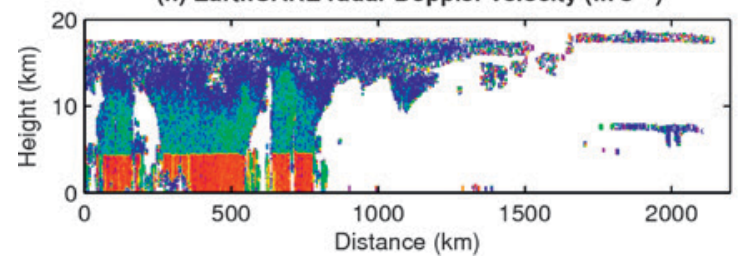

(b) CALIPSO attenuated lidar backscatter $\left(\mathrm{m}^{-1} \mathrm{sr}^{-1}\right)$
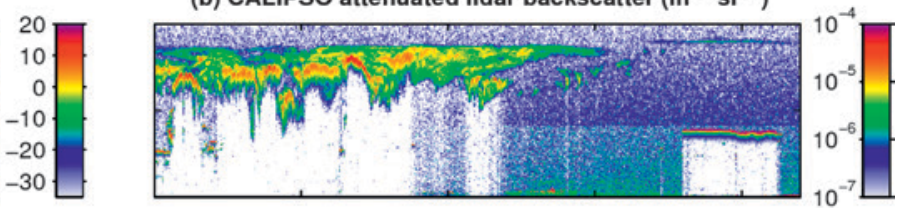

Mixture of liquid cloud and rain

Rain

Mixture of ice and supercooled liquid water

Ice cloud

Liquid cloud

Aerosol

Clear sky

Ground or sea

(e) Random error in natural logarithm of extinction coefficient

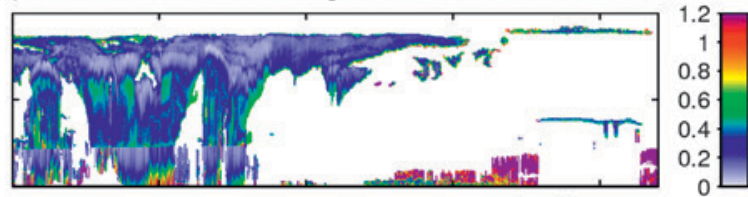

(g) EarthCARE lidar Mie channel $\left(\mathrm{m}^{-1} \mathrm{sr}^{-1}\right)$

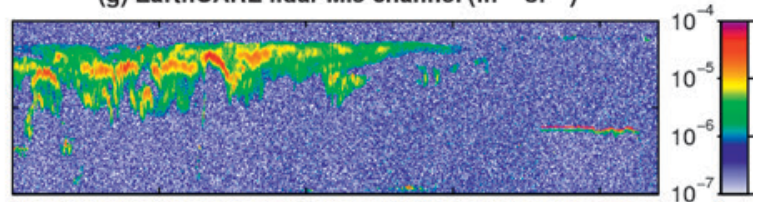

(i) EarthCARE lidar Rayleigh channel $\left(\mathrm{m}^{-1} \mathrm{sr}^{-1}\right)$
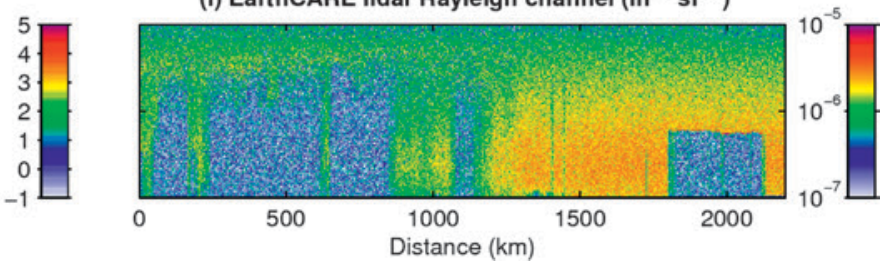

FIG. 9. Demonstration of what EarthCARE would see for a nighttime A-Train case: (a) CloudSat radar reflectivity factor at the start of granule 0363 I on 2 Jan 2007, where the image starts over New Guinea and ends over Australia; (b) corresponding CALIOP 532-nm apparent backscatter; (c) target classification; (d) extinction coefficient in the geometric optics approximation for the cloud, aerosol, and precipitation retrieved by the CAPTIVATE retrieval algorithm; (e) corresponding error in extinction; (f) simulated EarthCARE radar reflectivity factor from the retrievals; (g) simulated EarthCARE lidar attenuated backscatter in the Mie channel averaged to I-km along track; (h) simulated EarthCARE Doppler velocity averaged to 5-km along track; and (i) simulated EarthCARE backscatter in the Rayleigh channel averaged to I-km along track. 
Canadian Centre for Climate Modelling and Analysis (CCCma) (von Salzen et al. 2013), and the Rapid Radiative Transfer Model (Clough et al. 2005) - are each used to compute SW and LW fluxes and heating rate profiles for each retrieved column of width about $1 \mathrm{~km}$. These models are widely used in the GCM and NWP community. A small 3D atmosphere (on the order of ten to a few tens of square kilometers) is constructed around the retrieved cross section (Barker et al. 2011) by comparing the MSI radiances for an offnadir (recipient) pixel to corresponding nearby values along the nadir. Column properties of the nadir pixel whose MSI values best resemble those of the recipient are replicated at the recipient. This yields $3 \mathrm{D}$ domains of about $15-\mathrm{km}$ perpendicular distance to the orbit track. Figure 11 shows a schematic of the scene construction process. Figure 12 displays MODIS images
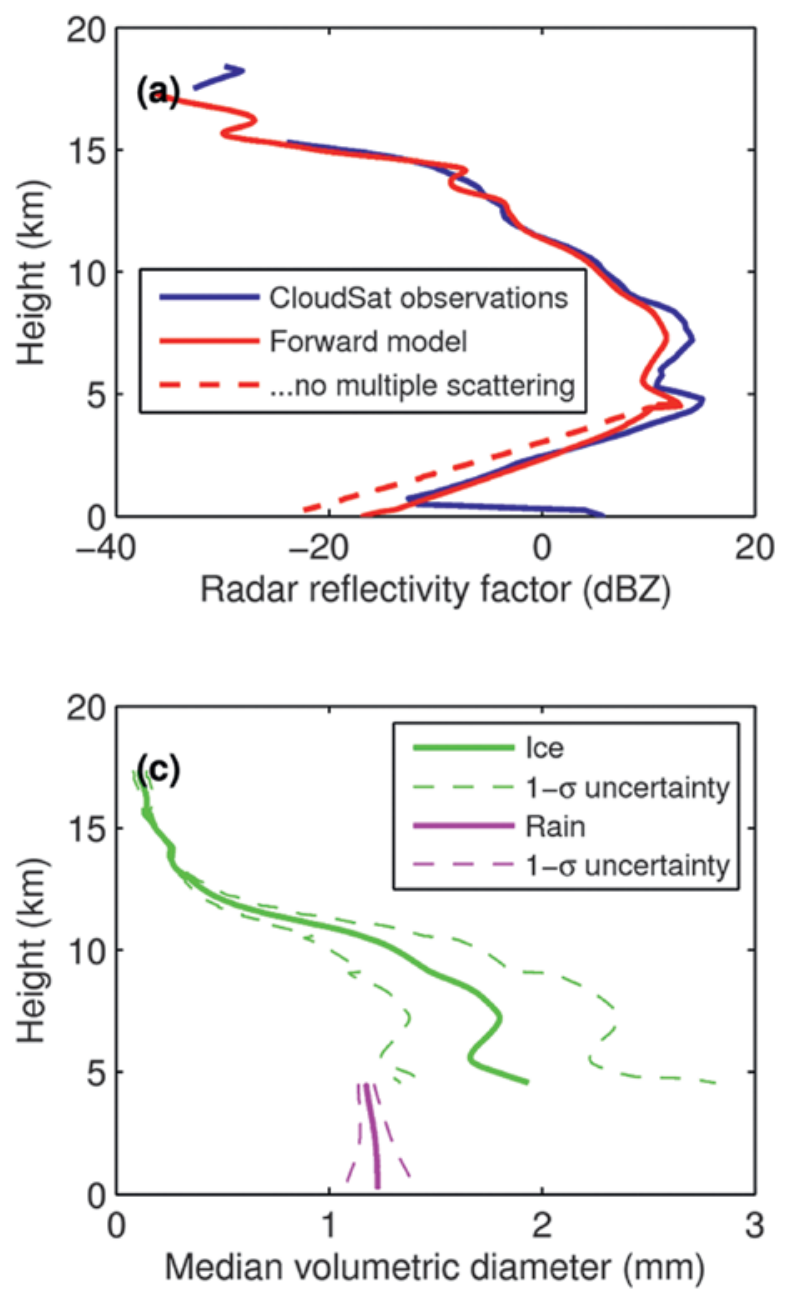

and their reconstructed counterparts in addition to broadband radiances computed by the $3 \mathrm{D} \mathrm{LW}$ model for a small portion of the constructed domain. A-Train data used here preceded those used in Fig. 9 by $\sim 12 \mathrm{~h}$ and were $\sim 1,000 \mathrm{~km}$ to the west. Broadband Monte Carlo parallelized 3D radiative transfer models (Barker et al. 2012) can then be employed to provide rapid yet accurate computation of radiances and fluxes on the joint standard grid as an operational product. Uncertainties are estimated by stochastically varying the reconstructed $3 \mathrm{D}$ atmosphere.

Once uncertainties for computed quantities, measured radiances, and ADM-derived broadband TOA fluxes are available, one may ask what is the probability $f_{\triangle F^{*}}$ that simulated and ADM-derived TOA fluxes, when averaged to $\sim 100-\mathrm{km}^{2}$ assessment domains, differ by less than $\Delta F^{*}$ ? This represents the
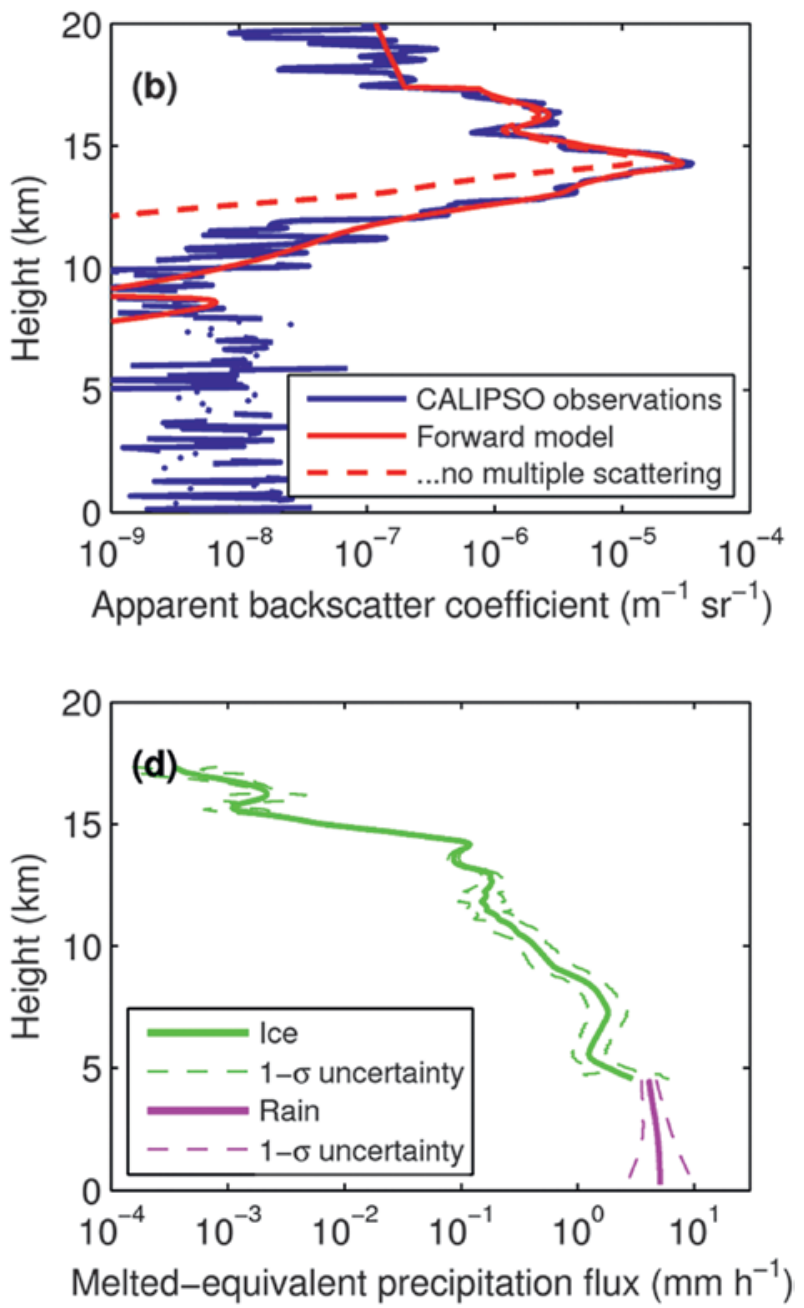

FIG. 10. Demonstration of the CAPTIVATE synergistic retrieval for a profile from Fig. 9 at a horizontal distance of $400 \mathrm{~km}$. (a),(b) The A-Train observations in blue and the corresponding forward-modeled values at the final iteration of the algorithm in red. The forward-modeled values omitting multiple scattering are shown by the red dashed lines. (c),(d) Retrieved properties of ice-cloud/snow (green) and rain (magenta) and their onestandard-deviation uncertainties. 
essence of EarthCARE radiative closure assessment. Nominally, if $f_{\Delta F^{*}}>0.5$ at $\Delta F^{*} \approx 10 \mathrm{~W} \mathrm{~m}^{-2}$ for a domain containing aerosol or cloud, most would likely conclude that EarthCARE's goal was achieved. Closure assessment is demonstrated best with end-to-end simulations, using the full representative L2 retrieval chain, but we are unable to do those as yet. Hence, results are shown in Fig. 12 for a mock assessment using the A-Train data mentioned above. A control case using the $3 \mathrm{D}$ scene constructed from A-Train retrievals represents flux estimates derived from $\mathrm{BBR}$ radiances. Uncertainty of $\pm 5 \%$ of TOA flux was used to represent errors due to ADMs (Kato and Loeb 2005). The experiment used 15 random perturbations of the same scene to affect input uncertainties in the form of unbiased and uncorrelated Gaussian noise (relative standard deviations of $\sim 30 \%$ at the bases of deep clouds and decreasing with altitude) added to profiles of cloud water content and particle size. Figure 12 shows that for this best case (unbiased retrievals) $\sim 90 \%$ of the $100-\mathrm{km}^{2}$ assessment domains have uncertainties $<10 \mathrm{~W} \mathrm{~m}^{-2}$. Once realistic retrieval uncertainties and other atmospheric and surface uncertainties are included, success rates will decrease but are nevertheless expected to exceed $\sim 75 \%$.

VERIFICATION AND VALIDATION. Verification and validation of EarthCARE products requires correlative observations of cloud, aerosol, precipitation, and radiation properties. The validation plan is to identify requirements, activities, and scientific teams for 1) validation by long-term ground- based observation networks, 2) satellite-to-satellite intercomparisons, and 3) field campaigns. Data from global or regional networks of ground-based systems, such as Aerosol Robotic Network (AERONET) and SKYNET radiometer networks (Holben et al. 1998; Nakajima et al. 2007), or the European Aerosol Research Lidar Network (EARLINET) and MicroPulse Lidar Network (MPLNET) (Pappalardo et al. 2010; Welton et al. 2001), can be used to validate EarthCARE products through statistical approaches as was done for CloudSat (Protat et al. 2010) and CALIPSO (Pappalardo et al. 2010; Omar et al. 2013). The intercomparisons with satellites-such as CloudSat, CALIPSO, Aqua, Terra, National Polar-Orbiting Operational Environmental Satellite System Prepatory Project (NPP), Geostationary Earth Radiation Budget (GERB), Global Change Observation Mission-Water (GCOM-W), and Global Change Observation Mission-Climate (GCOM-C)-will be an important contribution to complement ground-based observations in remote areas. The satellite-to-satellite validation will be worth exploiting once there are enough individual coincidences available. Field campaigns with mobile ground-based instruments and airborne systems are a very important part of the validation strategy, in particular for clouds with their small spatial structures and short temporal correlations. Cloud validation will be specifically addressed by mobile radars, such as the National Institute of Information and Communication Technology's (NICT) new ground-based $94-\mathrm{GHz}$ Doppler radar that was developed from the prototype

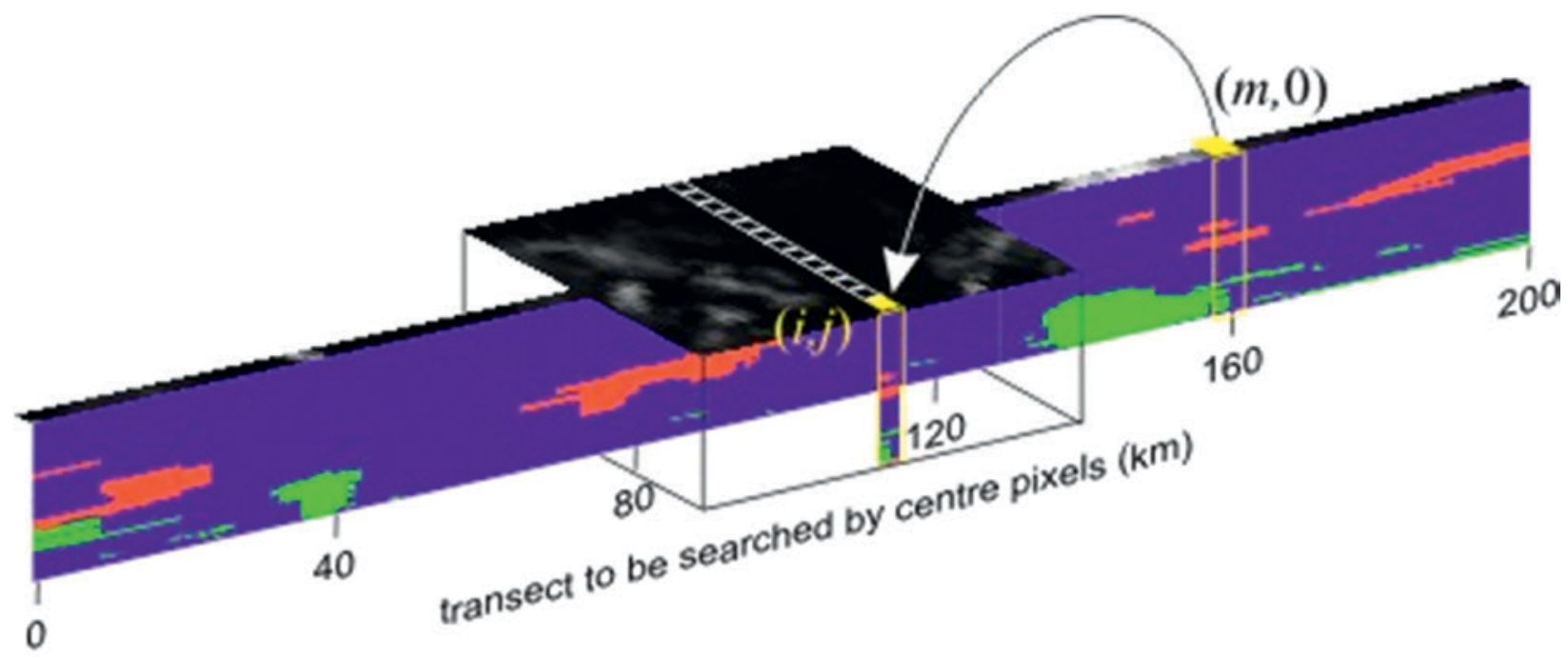

FIG. II. Broadening the narrow radar/lidar swath through comparison of MSI spectral radiances at off-nadir pixel $(i, j)$ with radiances from pixels along the retrieved cross section $(j=0)$. The nadir retrieved column associated with pixel $(m, 0)$ has been designated by the scene construction algorithm as the proxy for pixel $(i, j)$. As such, profiles of retrieved cloud and aerosol attributes at $(m, 0)$ get replicated at $(i, j)$ (Barker at el. $20 \mathrm{II})$. 

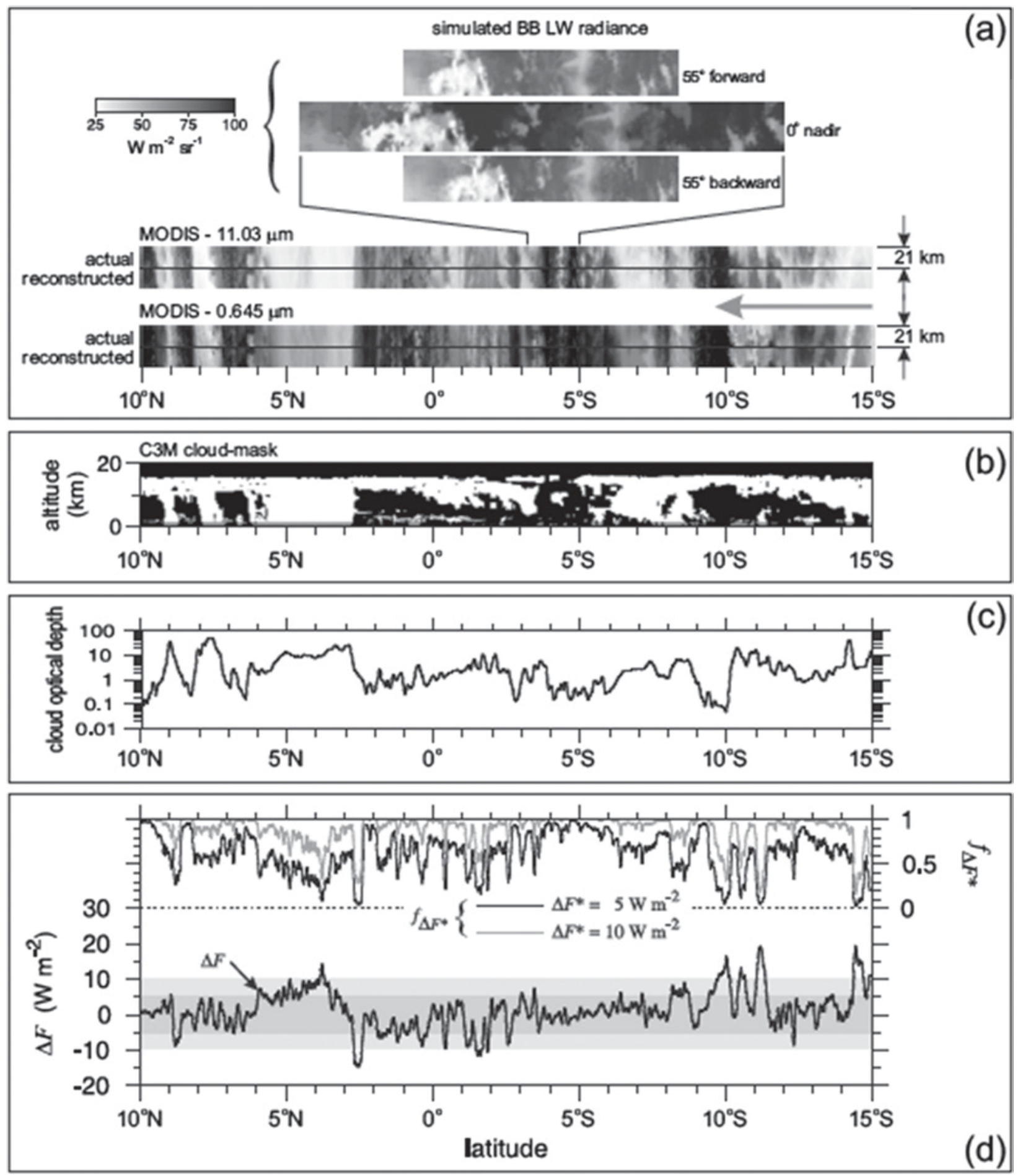

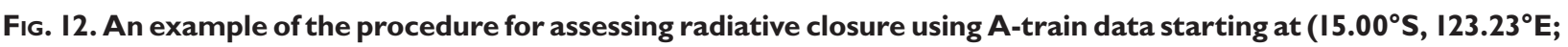
0536:36 UTC) and ending at $\left(10.00^{\circ} \mathrm{N}, \mathrm{II} .86^{\circ} \mathrm{E} ; 0543: 48 \mathrm{UTC}\right)$ on $2 \mathrm{Jan} 2007$. (a) Actual and reconstructed $21-\mathrm{km}-$ wide MODIS images (II.03 and $0.645 \mu \mathrm{m}$ ). Arrow indicates satellite tracking directions. (top) Broadband radiances, coregistered at altitude $15 \mathrm{~km}$, simulated by a 3D LW Monte Carlo model acting on the constructed 3D domain. Off-nadir views were scaled along track by $\cos \left(55^{\circ}\right)$, and unlike MODIS images, these have proper aspect ratios. (b) CloudSat-CALIPSO-CERES (C3M) cloud mask (white = ice; gray = liquid). (c) Mean visible cloud optical depth for assessment domains measuring $(\mathrm{II} \mathrm{km})^{2}$ centered on the CloudSat-CALIPSO cross section. (d) Difference $\Delta F$ in assessment domain mean TOA flux as computed by a 3D SW Monte Carlo algorithm applied to control and experimental atmospheres as described in the text. Here, $\sim 4.5 \times 10^{8}$ photons were injected over the full frame (comparable to that expected for EarthCARE) so Monte Carlo noise was negligible; $f \Delta_{F^{*}}$ is the probability that $\Delta F$ $<\Delta F^{*}$ for $\Delta F^{*}$ equal to 5 and $10 \mathrm{~W} \mathrm{~m}^{-2}$ assuming that uncertainties for TOA fluxes follow Gaussian distributions. 
EarthCARE CPR. Aircraft operating remote sensing instrumentation similar to the EarthCARE payload will underfly the EarthCARE satellite to verify microphysical retrievals. Correlative observations from ground-based sites, aircraft, and other satellites will be identified over the coming years and their readiness will be reviewed at a Joint European Space Agency (ESA)-Japan Aerospace Exploration Agency (JAXA) Validation Workshop prior to launch.

CHALLENGE AND SUMMARY. The IPCC (2013) has reiterated our low confidence in the ability to model cloud, aerosol, and precipitation processes. EarthCARE's Doppler cloud profiling radar and highspectral-resolution lidar are challenging instruments to be deployed in space. By careful design and with opportunities for synergistic retrievals, the mission promises to revolutionize our ability both to understand cloud, aerosol, and precipitation processes and their response to different atmospheric processes, while simultaneously evaluating and improving models. In the introduction, we gave examples of the shortcomings of current models in representing vertical profiles of aerosol, boundary layer cloud occurrence, mean ice water path, regional radiation biases, and the radiative impact of subvisual cirrus and midlevel thin supercooled cloud layers. Below we anticipate how EarthCARE should help to resolve these issues:

1) The HSRL can provide absolute and accurate measurements of extinction coefficient and lidar ratio. For example, it should estimate an aerosol layer of optical depth of 0.2 with an accuracy of $7 \%$ over a $50-\mathrm{km}$ horizontal resolution. Improved extinction profiles should lead to much better consistency between cloud/aerosol retrievals and broadband radiation measurements. Though ATLID's wavelength is different from CALIPSO's it is anticipated that EarthCARE will extend and refine the valuable record of global lidar aerosol measurements began by CALIPSO.

2) A sophisticated aerosol classification allowing for a quantification of absorbing and nonabsorbing, natural, and manmade particle types will be possible using the lidar and depolarization ratios observed with the HSRL and size information from the MSI. Accurate estimates of the anthropogenic versus the natural radiative impact of aerosols on the global and the regional scales will thus be feasible.

3) With $7 \mathrm{~dB}$ more sensitivity than CloudSat, we expect the CPR will detect substantially more thin cirrus and stratocumulus than is currently possible.

4) The CAPTIVATE synergistic retrievals using the CPR, HSRL, and MSI should yield accurate profiles of ice content, rain rates, particle size, and extinction with quantified uncertainties. For example, in ice clouds detected by the radar and lidar, we expect extinction and ice-water-content uncertainties of only $10 \%-20 \%$. There will be more occasions when clouds are detected by both the lidar and radar so that, using the MSI and the optimal-estimation approach, much improved 3D scenes can be retrieved.

5) TOA fluxes predicted to within $10 \mathrm{~W} \mathrm{~m}^{-2}$ from these 3D scenes of size $10 \mathrm{~km} \times 10 \mathrm{~km}$ can be compared with these values observed by the broadband radiometer and those analyzed in forecast models and climate models. This should help resolve problems such as the "too few, too bright" low tropical cloud problem and the reported regional and seasonal biases of up to $\pm 30 \mathrm{~W} \mathrm{~m}^{-2}$ in model TOA fluxes.

6) The more sensitive radar combined with the Doppler capability should yield more accurate snowfall and rainfall seasonal and regional climatologies, together with better characterization of drizzle production in warm clouds, ice crystal fluxes from thin supercooled layer clouds, and the degree of riming in ice clouds.

7) Doppler velocity estimates in stratiform regions should be within $0.5 \mathrm{~m} \mathrm{~s}^{-1}$ for $5 \mathrm{~km}$ along track, thus providing information on terminal velocities of ice particles, drizzle, rain, and snow and insights into drizzle production and riming. Longer averaging will provide ice fall speed of sufficient accuracy to provide a very useful constraint for global models, in which the radiation budget has been found to be very sensitive to the fall speed prescribed (Jakob 2002).

8) The Doppler capability should extend the knowledge (Luo et al. 2010) gained from CloudSat on convective motions and entrainment processes.

ACKNOWLEDGMENTS. The scientific exploitation of the EarthCARE mission is being prepared by a large team in Europe, Japan, and Canada who are preparing the science data retrieval algorithms, validation, and utilization. The authors wish to acknowledge specifically Michael Eisinger, Torsten Fehr, and Robert Koopman (ESA) together with the technical teams at ESA, JAXA and in industry whose expertise has been crucial in implementing such a challenging mission. 


\section{REFERENCES}

Amiridis, V., and Coauthors, 2013: Optimizing CALIPSO Saharan dust retrievals. Atmos. Chem. Phys., 13, 12 089-12 106, doi:10.5194/acp-13-12089-2013.

Baars, H., and Coauthors, 2012: Aerosol profiling with lidar in the Amazon Basin during the wet and dry season. J. Geophys. Res., 117, D21201, doi:10.1029/2012JD018338.

Barker, H. W., M. P. Jerg, T. Wehr, S. Kato, D. Donovan, and R. Hogan, 2011: A 3D cloud construction algorithm for the EarthCARE satellite mission. Quart. J. Roy. Meteor. Soc., 137, 1042-1058, doi:10.1002/qj.824.

—, S. Kato, and T. Wehr, 2012: Computation of solar radiative fluxes by $1 \mathrm{D}$ and $3 \mathrm{D}$ methods using cloudy atmospheres inferred from A-train satellite data. Surv. Geophys., 33, 657-676, doi:10.1007 /s10712-011-9164-9.

Battaglia, A., and S. Tanelli, 2011: Doppler multiple scattering simulator. IEEE Trans. Geosci. Remote Sens., 49, 442-450, doi:10.1109/TGRS.2010.2052818.

— ing the EarthCARE Doppler radar mispointing. IEEE Trans. Geosci. Remote Sens., 53, 2079-2085, doi:10.1109/TGRS.2014.2353219.

Berg, W., T. L'Ecuyer, and J. M. Haynes, 2010: The distribution of rainfall over oceans from spaceborne radars. J. Appl. Meteor. Climatol., 49, 535-543, doi:10.1175/2009JAMC2330.1.

Bony, S., and B. Stevens, 2012: Clouds, circulation and climate sensitivity: How the interactions between clouds, greenhouse gases and aerosols affect temperature and precipitation in a changing climate. WCRP Grand Challenge White Paper 4, 7 pp. [Available online at www.wcrp-climate.org/images/documents /grand_challenges/GC4_Clouds_14nov2012.pdf.]

Burton, S. P., and Coauthors, 2012: Aerosol classification using airborne High Spectral Resolution Lidar measurements-Methodology and examples. Atmos. Meas. Tech., 5, 73-98, doi:10.5194/amt-5-73-2012.

Ceccaldi, M., J. Delanoë, R. J. Hogan, N. L. Pounder, A. Protat, and J. Pelon, 2013: From CloudSat-CALIPSO to EarthCare: Evolution of the DARDAR cloud classification and its validation using airborne radar-lidar observations. J. Geophys. Res. Atmos., 118, 7962-7981, doi:10.1002/jgrd.50579.

Clerbaux, N., S. Dewitte, L. Gonzalez, C. Bertrand, B. Nicula, and A. Ipe, 2003: Outgoing longwave flux estimation: Improvement of angular modelling using spectral information. Remote Sens. Environ., 85, 389-395, doi:10.1016/S0034-4257(03)00015-4.

Clough, S. A., M. W. Shephard, E. J. Mlawer, J. S. Delamere, M. J. Iacono, K. Cady-Pereira, S. Boukabara, and P. D. Brown, 2005: Atmospheric radiative transfer modeling: A summary of the AER codes. J. Quant. Spectrosc. Radiat. Transfer, 91, 233-244, doi:10.1016/j .jqsrt.2004.05.058.

Delanoë, J., and R. J. Hogan, 2010: Combined CloudSatCALIPSO-MODIS retrievals of the properties of ice clouds. J. Geophys. Res., 115, D00H29, doi:10.1029 /2009JD012346.

,,-- R. M. Forbes, A. Bodas-Salcedo, and T. H. M. Stein, 2011: Evaluation of ice cloud representation in the ECMWF and UK Met Office models using CloudSat and CALIPSO data. Quart. J. Roy. Meteor. Soc., 137, 2064-2078, doi:10.1002/qj.882.

Deng, M., G. G. Mace, Z. Wang, and H. Okamoto, 2010: Tropical composition, cloud and climate coupling experiment validation for cirrus cloud profiling retrieval using CloudSat radar and CALIPSO lidar. J. Geophys. Res., 115, D00J15, doi:10.1029/2009JD013104.

Domenech, C., and T. Wehr, 2011: Use of artificial neural networks to retrieve TOA SW radiative fluxes for the EarthCARE mission. IEEE Trans. Geosci. Remote Sens., 49, 1839-1849, doi:10.1109 /TGRS.2010.2102768.

— - — , and J. Fischer, 2011: Toward an Earth Clouds, Aerosols and Radiation Explore (EarthCARE) thermal flux determination: Evaluation using Clouds and the Earth's Radiant Energy System (CERES) true along-track data. J. Geophys. Res., 116, D06115, doi:10.1029/2010JD015212.

Donovan, D. P., and Coauthors, 2001: Cloud effective particle size and water content profile retrievals using combined lidar and radar observations: 2. Comparison with IR radiometer and in situ measurements in ice clouds. J. Geophys. Res., 106, 27 449-27 464, doi:10.1029/2001JD900241.

Dufresne, J.-L., and S. Bony, 2008: An assessment of the primary sources of spread of global warming estimates from coupled atmosphere-ocean models. J. Climate, 21, 5135-5144, doi:10.1175/2008JCLI2239.1.

Durand, Y., A. Hélière, J.-L. Bézy, and R. Meynart, 2007: The ESA EarthCARE mission: Results of the ATLID instrument pre-developments. Lidar Technologies, Techniques, and Measurements for Atmospheric Remote Sensing III, U. N. Singh and G. Pappalardo, International Society for Optical Engineering (SPIE Proceedings, Vol. 6750), 675015, doi:10.1117/12.737932.

Fu, Q., and K.-N. Liou, 1992: On the correlated k-distribution method for radiative transfer in nonhomogenous atmospheres. J. Atmos. Sci., 49, 2139-2156, doi:10.1175/1520-0469(1992)049<2139:OTCDMF $>2.0 . \mathrm{CO} ; 2$. 
Groß, S. V., M. Tesche, V. Freudenthaler, C. Toledano, M. Wiegner, A. Ansmann, D. Althausen, and M. Seefeldner, 2011: Characterization of Saharan dust, marine aerosols and mixtures of biomassburning aerosols and dust by means of multiwavelength depolarization and Raman lidar measurements during SAMUM 2. Tellus, 63B, 706-724, doi:10.1111/j.1600-0889.2011.00556.x.

— , V. Freudenthaler, M. Wiegner, J. Gasteiger, A. Geiß, and F. Schnell, 2012: Dual-wavelength linear depolarization ratio of volcanic aerosols: Lidar measurements of the Eyjafjallajökull plume over Maisach, Germany. Atmos. Environ., 48, 85-96, doi:10.1016/j .atmosenv.2011.06.017.

Hagihara, Y., H. Okamoto, and R. Yoshida, 2010: Development of a combined CloudSatCALIPSO cloud mask to show global cloud distribution. J. Geophys. Res., 115, D00H33, doi:10.1029/2009JD012344.

Hashino, T., M. Satoh, Y. Hagihara, T. Kubota, T. Matsui, T. Nasuno, and H. Okamoto, 2013: Evaluating cloud microphysics from NICAM against CloudSat and CALIPSO. J. Geophys. Res., 118, 7273-7292, doi:10.1002/jgrd.50564.

Higurashi, A., T. Nakajima, B. N. Holben, A. Smirnov, R. Frouin, and B. Chatenet, 2000: A study of global aerosol optical climatology with two-channel AVHRR remote sensing. J. Climate, 13, 2011-2027, doi:10.1175/1520-0442(2000)013<2011:ASOGAO $>2.0 . \mathrm{CO} ; 2$.

Hogan, R. J., 2008: Fast lidar and radar multiplescattering models. Part I: Small-angle scattering using the photon variance-covariance method. J. Atmos. Sci., 65, 3621-3635, doi:10.1175/2008JAS2642.1.

— , and C. D. Westbrook, 2014: Equation for the microwave backscatter cross section of aggregate snowflakes using the self-similar Rayleigh-Gans approximation.J.Atmos. Sci., 71,3292-3301, doi:10.1175 /JAS-D-13-0347.1.

Holben, B. N., and Coauthors, 1998: AERONET-A federated instrument network and data archive for aerosol characterization. Remote Sens. Environ., 66, 1-16, doi:10.1016/S0034-4257(98)00031-5.

Horie, H., Y. Ohno, K. Sato, K. Nakagawa, and N. Takahashi, 2012: Doppler velocity calibration study for cloud profiling radar on EarthCARE. Proc. IGARSS 2012, Munich, Germany, IEEE, 4629-4632, doi:10.1109/IGARSS.2012.6350434.

Illingworth, A. J., and Coauthors, 2007: Cloudnet: Continuous evaluation of cloud profiles in seven operational models using ground-based observations. Bull. Amer. Meteor. Soc., 88, 883-898, doi:10.1175/BAMS-88-6-883.
IPCC, 2013: Summary for policymakers. Climate Change 2013: The Physical Science Basis, T. F. Stocker et al., Eds., Cambridge University Press, 1-29.

Ishida, H., and T. Y. Nakajima, 2009: Development of an unbiased cloud detection algorithm for a spaceborne multispectral imager. J. Geophys. Res., 114, D07206, doi:10.1029/2008JD010710.

Jakob, C., 2002: Ice clouds in numerical weather prediction models: Progress, problems, and prospects. Cirrus, D. K. Lynch et al. Eds., Oxford University Press, 327-345.

Janisková, M., P. Lopez, and P. Bauer, 2012: Experimental $1 \mathrm{D}+4 \mathrm{D}$-Var assimilation of CloudSat observations. Quart. J. Roy. Meteor. Soc., 138, 1196-1220, doi:10.1002/qj.988.

Kanitz, T., A. Ansmann, R. Engelmann, and D. Althausen, 2013: North-south cross sections of the vertical aerosol distribution over the Atlantic Ocean from multiwavelength Raman/polarization lidar during Polarstern cruises. J. Geophys. Res. Atmos., 118, 2643-2655, doi:10.1002/jgrd.50273.

Kato, S., and N. G. Loeb, 2005: Top-of-atmosphere shortwave broadband observed radiance and estimated irradiance over polar regions from Clouds and the Earth's Radiant Energy System (CERES) instruments on Terra. J. Geophys. Res., 110, D07202, doi:10.1029/2004JD005308.

Koffi, B., and Coauthors, 2012: Application of the CALIOP layer product to evaluate the vertical distribution of aerosols estimated by global models: AeroCom phase I results. J. Geophys. Res., 117, D10201, doi:10.1029/2011JD016858.

Kollias, P., S. Tanelli, A. Battaglia, and A. Tatarevic, 2014: Evaluation of EarthCARE cloud profiling radar Doppler velocity measurements in particle sedimentation regimes. J. Atmos. Oceanic Technol., 31, 366-386, doi:10.1175/JTECH-D-11 -00202.1.

Lebsock, M. D., T. S. L'Ecuyer, and G. L. Stephens, 2011: Detecting the ratio of rain and cloud water in low-latitude shallow marine clouds. J. Appl. Meteor. Climatol., 50, 419-432, doi:10.1175 /2010JAMC2494.1.

L'Ecuyer, T. S., and G. L. Stephens, 2002: An estimation-based precipitation retrieval algorithm for attenuating radars. J. Appl. Meteor., 41, 272-285, doi:10.1175/1520-0450(2002)041<0272:AEBPRA $>2.0 . \mathrm{CO} ; 2$.

Li, J.-L. F., and Coauthors, 2012: An observationally based evaluation of cloud ice water in CMIP3 and CMIP5 GCMs and contemporary reanalyses using contemporary satellite data. J. Geophys. Res., 117, D16105, doi:10.1029/2012JD017640. 
— - E. Waliser, G. Stephens, S. Lee, T. L'Ecuyer, S. Kato, N. Loeb, and H.-Y. Ma, 2013: Characterizing and understanding radiation budget biases in CMIP3/ CMIP5 GCMs, contemporary GCM, and reanalysis. J. Geophys. Res. Atmos., 118, 8166-8184, doi:10.1002 /jgrd.50378.

Liu, G., 2008: Deriving snow cloud characteristics from CloudSat observations. J. Geophys. Res., 113, D00A09, doi:10.1029/2007JD009766.

Loeb, N. G., S. Kato, K. Loukachine, and N. ManaloSmith, 2005: Angular distribution models for top-ofatmosphere radiative flux estimation from the Clouds and the Earth's Radiant Energy System instrument on the Terra satellite. Part I: Methodology. J. Atmos. Oceanic Technol., 22, 338-351, doi:10.1175 /JTECH1712.1.

Luo, Z. J., G. Y. Liu, and G. L. Stephens, 2010: Use of A-Train data to estimate convective buoyancy and entrainment rate. Geophys. Res. Lett., 37, L09804, doi:10.1029/2010GL042904.

Matrosov, S., 2007: Potential for attenuation-based estimates of rainfall rate from CloudSat. Geophys. Res. Lett., 34, L05817, doi:10.1029/2006GL029161.

Müller, D., A. Ansmann, I. Mattis, M. Tesche, U. Wandinger, D. Althausen, and G. Pisani, 2007: Aerosol-type-dependent lidar ratios observed with Raman lidar. J. Geophys. Res., 112, D16202, doi:10.1029/2006JD008292.

Nakajima, T., and Coauthors, 2007: Overview of the Atmospheric Brown Cloud East Asian Regional Experiment 2005 and a study of the aerosol direct radiative forcing in east Asia. J. Geophys. Res., 112, D24S91, doi:10.1029/2007JD009009.

Nakajima, T. Y., K. Suzuki, and G. L. Stephens, 2010: Droplet growth in warm water clouds observed by the A-Train. Part II: A multisensor view. J. Atmos. Sci., 67, 1897-1907, doi:10.1175/2010JAS3276.1.

Nam, C., S. Bony, J.-L. Dufresne, and H. Chepfer, 2012: The 'too few, too bright' tropical low-cloud problem in CMIP5 models. Geophys. Res. Lett., 39, L21801, doi:10.1029/2012GL053421.

Nishizawa, T., N. Sugimoto, I. Matsui, A. Shimizu, B. Tatarov, and H. Okamoto, 2008: Algorithm to retrieve aerosol optical properties from high-spectralresolution lidar and polarization Mie-scattering lidar measurements. IEEE Trans. Geosci. Remote Sens., 46, 4094-4103, doi:10.1109/TGRS.2008.2000797.

— - and Coauthors, 2011: Algorithms to retrieve optical properties of three-component aerosols from two-wavelength backscatter and one-wavelength polarization lidar measurements considering nonsphericity of dust. J. Quant. Spectrosc. Radiat. Transfer, 112, 254-267, doi:10.1016/j.jqsrt.2010.06.002.
Oikawa, E., T. Nakajima, T. Inoue, and D. Winker, 2013: A study of the shortwave direct aerosol forcing using ESSP/CALIPSO observation and GCM simulation. J. Geophys. Res. Atmos., 118, 3687-3708, doi:10.1002 /jgrd.50227.

Okamoto, H., S. Iwasaki, M. Yasui, H. Horie, H. Kuroiwa, and H. Kumagai, 2003: An algorithm for retrieval of cloud microphysics using $95-\mathrm{GHz}$ cloud radar and lidar. J. Geophys. Res., 108, 4226, doi:10.1029/2001JD001225.

— , and Coauthors, 2007: Vertical cloud structure observed from shipborne radar and lidar: Midlatitude case study during the MR01/K02 cruise of the research vessel Mirai. J. Geophys. Res., 112, D08216, doi:10.1029/2006JD007628.

_- and Coauthors, 2008: Vertical cloud properties in the tropical western Pacific Ocean: Validation of the CCSR/NIES/FRCGC GCM by shipborne radar and lidar. J. Geophys. Res., 113, D24213, doi:10.1029/2008JD009812.

—, K. Sato, and Y. Hagihara, 2010: Global analysis of ice microphysics from CloudSat and CALIPSO: Incorporation of specular reflection in lidar signals. J. Geophys. Res., 115, D22209, doi:10.1029 /2009JD013383.

Omar, A. H., and Coauthors, 2009: The CALIPSO automated aerosol classification and lidar ratio selection algorithm. J. Atmos. Oceanic Technol., 26, 1994-2014, doi:10.1175/2009JTECHA1231.1.

_- and Coauthors, 2013: CALIOP and AERONET aerosol optical depth comparisons: One size fits none. J. Geophys. Res. Atmos., 118, 4748-4766, doi:10.1002/jgrd.50330.

Pappalardo, G., and Coauthors, 2010: EARLINET correlative measurements for CALIPSO: First intercomparison results. J. Geophys. Res., 115, D00H19, doi:10.1029/2009JD012147.

Pérez Albiñana, A., and Coauthors, 2010: The multispectral imager on board the EarthCARE spacecraft. Infrared Remote Sensing and Instrumentation XVIII, M. Strojnik and G. Paez, Eds., International Society for Optical Engineering (SPIE Proceedings, Vol. 7808), 780-815, doi:10.1117/12.858864.

Protat, A., J. Delanoë, E. J. O'Connor, and T. S. L'Ecuyer, 2010: The evaluation of CloudSat and CALIPSO ice microphysical products using ground-based cloud radar and lidar observations. J. Atmos. Oceanic Technol., 27, 793-810, doi:10.1175 /2009JTECHA1397.1.

Proulx, C., M. Allard, T. Pope, B. Tremblay, F. Williamson, J. Delderfield, and D. Parker, 2010: EarthCARE BBR detectors performance characterization. Sensors, Systems, and Next-Generation Satellites XIV, R. 
Meynart, S. P. Neeck, and H. Shimoda, Eds., International Society for Optical Engineering (SPIE Proceedings, Vol. 7826), 78261T, doi:10.1117/12.868518.

Sato, K., and H. Okamoto, 2011: Refinement of global ice microphysics using spaceborne active sensors. J. Geophys. Res., 116, D20202, doi:10.1029 /2011JD015885.

—, H. Okamoto, M. K. Yamamoto, S. Fukao, H. Kumagai, Y. Ohno, H. Horie, and M. Abo, 2009: 95-GHz Doppler radar and lidar synergy for simultaneous ice microphysics and in-cloud vertical air motion retrieval. J. Geophys. Res., 114, D03203, doi:10.1029/2008JD010222.

Schutgens, N. A., 2008: Simulated Doppler radar observations of inhomogeneous clouds. J. Atmos. Oceanic Technol., 25, 26-42, doi:10.1175/2007JTECHA956.1.

Shipley, S., D. Tracy, E. Eloranta, J. Trauger, J. Sroga, F. Roesler, and J. Weinman, 1983: High spectral resolution lidar to measure optical scattering properties of atmospheric aerosols. 1: Theory and instrumentation. Appl. Opt., 22, 3716-3724, doi:10.1364/AO.22.003716.

Stephens, G. L., and Coauthors, 2008: CloudSat mission: Performance and early science after the first year of operation. J. Geophys. Res., 113, D00A18, doi:10.1029/2008JD009982.

Sun, W., G. Videen, S. Kato, B. Lin, C. Lukashin, and Y. Hu, 2011: A study of subvisual clouds and their radiation effect with a synergy of CERES, MODIS, CALIPSO, and AIRS data. J. Geophys. Res., 11, D22207, doi:10.1029/2011JD016422.

Suzuki, K., T. Y. Nakajima, and G. L. Stephens, 2010: Particle growth and drop collection efficiency of warm clouds as inferred from joint CloudSat and MODIS observations. J. Atmos. Sci., 67, 3019-3032, doi:10.1175/2010JAS3463.1.

Sy, O. O., S. Tanelli, N. Takahashi, Y. Ohno, H. Horie, and P. Kollias, 2014: Simulation of EarthCARE spaceborne Doppler radar products using ground-based and airborne data: Effects of aliasing and nonuniform beam-filling. IEEE Trans. Geosci. Remote Sens., 52, 1463-1479, doi:10.1109/TGRS.2013.2251639.

Tanelli, S., E. Im, S. L. Durden, L. Facheris, and D. Giuli, 2002: The effects of nonuniform beam filling on vertical rainfall velocity measurements with a spaceborne Doppler radar. J. Atmos. Oceanic Technol., 19, 1019-1034, doi:10.1175/1520-0426(2002)019<1019: TEONBF $>2.0 . \mathrm{CO} ; 2$.

Velázquez-Blázquez, A., and N. Clerbaux, 2010: Sensitivity study of the influence of a target spectral signature in the unfiltering process for broadband radiometers. ESA/ESTEC Final Rep., Contract 22460/09/NL/EL, $20 \mathrm{pp}$. [Available online at ftp://gerb.oma.be/almudena
/SITS_DB_compressed/GeoType_data_base_desc .pdf.]

von Hoyningen-Huene, W., M. Freitag, and J. P. Burrows, 2003: Retrieval of aerosol optical thickness over land surfaces from top-of-atmosphere radiance. J. Geophys. Res., 108, 4260-4279, doi:10.1029 /2001JD002018.

von Salzen, K., and Coauthors, 2013: The Canadian Fourth Generation Atmospheric Global Climate Model (CanAM4). Part I: Representation of physical processes. Atmos.-Ocean, 51, 104-125, doi:10.1080 /07055900.2012.755610.

Voors, R., and Coauthors, 2007: ECSIM: The simulator framework for EarthCARE. Sensors, Systems, and Next-Generation Satellites XI, R. Meynart et al., Eds., International Society for Optical Engineering (SPIE Proceedings, Vol. 6744), 67441Y, doi:10.1117/12.737738.

Watanabe, M., and Coauthors, 2010: Improved climate simulation by MIROC5: Mean states, variability, and climate sensitivity. J. Climate, 23, 6312-6335, doi:10.1175/2010JCLI3679.1.

Welton, E. J., J. R. Campbell, J. D. Spinhine, and V. S. Scott, 2001: Global monitoring of clouds and aerosols using a network of micro-pulse lidar systems. Lidar Remote Sensing for Industry and Environmental Monitoring, U. H. Singh, T. Itabe, and N. Sugimoto, Eds., International Society for Optical Engineering (SPIE Proceedings, Vol. 4153), $152-158$.

Winker, D. M., and Coauthors, 2010: The CALIPSO mission: A global 3D view of aerosols and clouds. Bull. Amer. Meteor. Soc., 91, 1211-1229, doi:10.1175 /2010BAMS3009.1.

Yoshida, R., H. Okamoto, Y. Hagihara, and H. Ishimoto, 2010: Global analysis of cloud phase and ice crystal orientation from Cloud-Aerosol Lidar and Infrared Pathfinder Satellite Observation (CALIPSO) data using attenuated backscattering and depolarization ratio. J. Geophys. Res., 115, D00H32, doi:10.1029/2009JD012334.

Young, S. A., and M. A. Vaughan, 2009: The retrieval of profiles of particulate extinction from Cloud-Aerosol Lidar Infrared Pathfinder Satellite Observations (CALIPSO) data: Algorithm description. J. Atmos. Oceanic Technol., 26, 1105-1119, doi:10.1175/2008JTECHA1221.1.

Zhang, D., Z. Want, and D. Liu, 2010: A global view of midlevel liquid-layer topped stratiform cloud distribution and phase partition from CALISPO and CloudSat measurements. J. Geophys. Res., 115, D00H13, doi:10.1029/2009JD012143. 